Linköping Studies in Science and Technology

Dissertation No. 1925

\title{
Quantum chemical studies of deposition and catalytic surface reactions
}

\author{
Emil Kalered
}

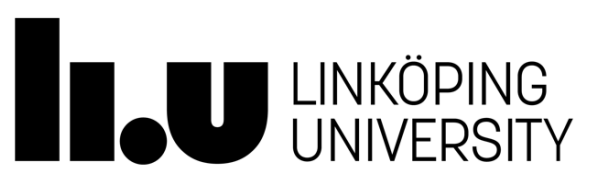

\author{
Division of Chemistry \\ Department of Physics, Chemistry and Biology \\ Linköping University, SE-581 83 Linköping, Sweden \\ Linköping 2018
}


(c) Copyright 2018 Emil Kalered, unless otherwise noted

Cover: A fictional reaction path in the silhouette of Linköping Cathedral and the $\mathrm{Zr}_{9} \mathrm{O}_{18}$ and $\mathrm{H}_{60} \mathrm{Si}_{33} \mathrm{C}_{33}$ clusters.

Published articles have been reprinted with the permission of the copyright holder.

Printed in Sweden by LiU-Tryck, Linköping, Sweden, 2018

ISBN 978-91-7685-333-7

ISSN 0345-7524 
Till Far och Mor.

"Dovie'andi se tovya sagain." - The wheel of time 



\section{Contents}

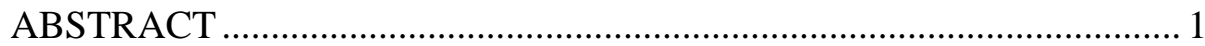

POPULÄRVETENSKAPLIG SAMMANFATTNING ................................ 5

LIST OF INCLUDED PUBLICATIONS ..................................................... 9

My contribution to the papers ............................................................... 10

Related, not included publications....................................................... 10

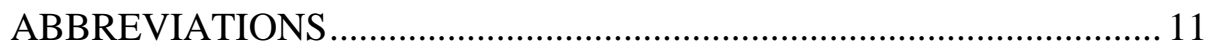

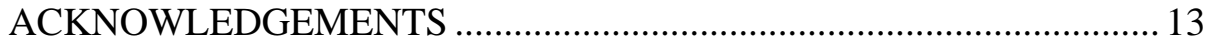

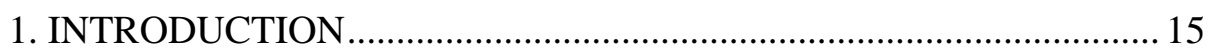

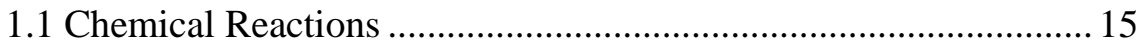

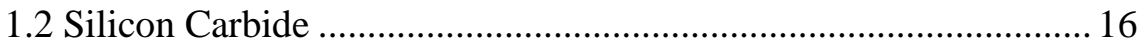

1.3 CVD of Silicon Carbide............................................................. 17

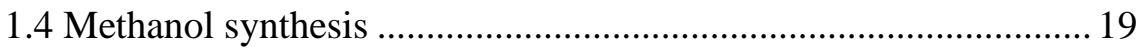

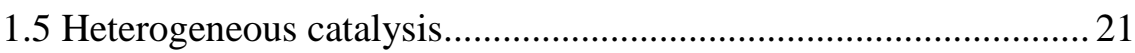

1.6 Methanol synthesis by heterogeneous catalysis ............................. 22

2. COMPUTATIONAL METHODS ………………............................... 23

2.1 Electron structure theory............................................................. 23

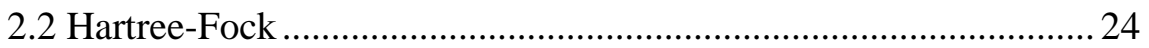

2.3 Density Functional Theory (DFT) ……………............................ 26

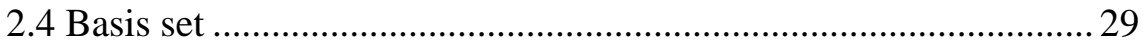

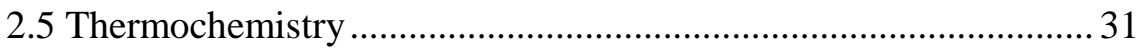

2.5.1 The Partition Function ……………………………………........ 31

2.5.2 Thermochemical Quantities ............................................................. 35

2.5.3 Thermochemical Equilibrium ...................................................... 36

2.5.4 Thermochemical Kinetics ............................................................ 38

2.6 Computational Model ................................................................... 41

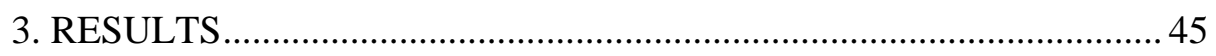

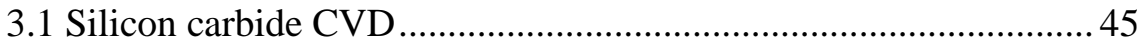


3.2 Methanol synthesis .............................................................. 52

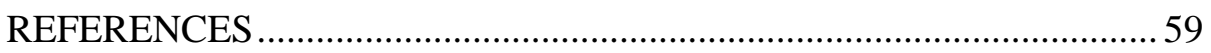

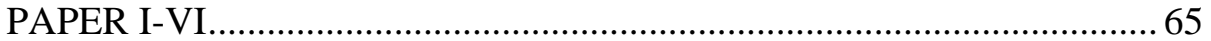




\section{Abstract}

Quantum chemical calculations have been used to model chemical reactions in epitaxial growth of silicon carbide by chemical vapor deposition (CVD) processes and to study heterogeneous catalytic reactions for methanol synthesis. CVD is a common method to produce high-quality materials and e.g. thin films in the semiconductor industry, and one of the many usages of methanol is as a promising future renewable and sustainable energy carrier. To optimize the chemical processes it is essential to understand the reaction mechanisms. A comprehensive theoretical model for the process is therefore desired in order to be able to explore various variables that are difficult to investigate in situ. In this thesis reaction paths and reaction energies are computed using quantum chemical calculations. The quantum-chemical results can subsequently be used as input for thermodynamic, kinetic and computational fluid dynamics modelling in order to obtain data directly comparable with the experimental observations.

For the CVD process, the effect of halogen addition to the gas mixture is studied by modelling the adsorption and diffusion of $\mathrm{SiH}_{2}, \mathrm{SiCl}_{2}$ and $\mathrm{SiBr}_{2}$ on the $(000 \overline{1}) 4 \mathrm{H}-\mathrm{SiC}$ surface. $\mathrm{SiH}_{2}$ was found to bind strongest to the surface and $\mathrm{SiBr}_{2}$ binds slightly stronger than the $\mathrm{SiCl}_{2}$ molecule. The diffusion barrier is shown to be lower for $\mathrm{SiH}_{2}$ than for $\mathrm{SiBr}_{2}$ and $\mathrm{SiCl}_{2}$ which have similar barriers. $\mathrm{SiBr}_{2}$ and $\mathrm{SiCl}_{2}$ are found to have similar physisorption energies and bind stronger than the $\mathrm{SiH}_{2}$ molecule. Gibbs free-energy calculations also indicate that the $\mathrm{SiC}$ surface is not fully hydrogen terminated at CVD conditions since missing-neighboring pair of surface hydrogens is found to be common. Calculations for the (0001) surface show that $\mathrm{SiCl}, \mathrm{SiCl}_{2}, \mathrm{SiHCl}, \mathrm{SiH}$, and $\mathrm{SiH}_{2}$ likely adsorb on a methylene site, but the processes are thermodynamically less favorable than their reverse reactions. However, the adsorbed products may be stabilized by subsequent surface reactions to form a larger structure. The formation of these larger structures is found to be fast enough to compete with the desorption processes. Also the Gibbs free energies for adsorption of $\mathrm{Si}$ atoms, $\mathrm{SiX}, \mathrm{SiX}_{2}$, 
and $\mathrm{SiHX}$ where $\mathrm{X}$ is $\mathrm{F}$ or $\mathrm{Br}$ are presented. Adsorption of $\mathrm{Si}$ atoms is shown to be the most thermodynamically favorable reaction followed by $\mathrm{SiX}$, $\mathrm{SiHX}$, and $\mathrm{SiX}_{2}, \mathrm{X}$ being a halide. The results in this study suggest that the major $\mathrm{Si}$ contributors in the $\mathrm{SiC}-\mathrm{CVD}$ process are $\mathrm{Si}$ atoms, $\mathrm{SiX}$ and $\mathrm{SiH}$.

Methanol can be synthesized from gaseous carbon dioxide and hydrogen using solid metal-metal oxide mixtures acting as heterogeneous catalysts. Since a large surface area of the catalyst enhances the speed of the heterogeneous reaction, the use of nanoparticles (NP) is expected to be advantageous due to the NPs' large area to surface ratio. The plasma-induced creation of copper NPs is investigated. One important element during particle growth is the charging process where the variation of the work function (W) with particle size is a key quantity, and the variation becomes increasingly pronounced at smaller NP sizes. The work functions are computed for a set of NP charge numbers, sizes and shapes, using copper as a case study. A derived analytical expression for $\mathrm{W}$ is shown to give quite accurate estimates provided that the diameter of the NP is larger than about a nanometer and that the NP has relaxed to close to a spherical shape. For smaller sizes $\mathrm{W}$ deviates from the approximative expression, and also depends on the charge number. Some consequences of these results for NP charging process are outlined.

Key reaction steps in the methanol synthesis reaction mechanism using a $\mathrm{Cu} / \mathrm{ZrO}_{2}$ nanoparticle catalyst is investigated. Two different reaction paths for conversion of $\mathrm{CO}_{2}$ to $\mathrm{CO}$ is studied. The two paths result in the same complete reaction $2 \mathrm{CO}_{2} \rightarrow 2 \mathrm{CO}+\mathrm{O}_{2}$ where $\mathrm{ZrO}_{2}$ (s) acts as a catalyst. The highest activation energies are significantly lower compared to that of the gas phase reaction. The presence of oxygen vacancies at the surface appear to be decisive for the catalytic process to be effective. Studies of the reaction kinetics show that when oxygen vacancies are present on the $\mathrm{ZrO}_{2}$ surface, carbon monoxide is produced within a microsecond. The IR spectra of $\mathrm{CO}_{2}$ and $\mathrm{H}_{2}$ interacting with $\mathrm{ZrO}_{2}$ and $\mathrm{Cu}$ under conditions that correspond to the catalyzed $\mathrm{CH}_{3} \mathrm{OH}$ production process is also studied experimentally and compared to results from the theoretical computations. Surface structures and gas-phase molecules are identified through the spectral lines by matching them to specific vibrational modes from the literature and from the 
new computational results. Several surface structures are verified and can be used to pin point surface structures in the reaction path. This gives important information that help decipher how the reaction mechanism of the $\mathrm{CO}_{2}$ conversion and ultimately may aid to improve the methanol synthesis process. 


\section{Populärvetenskaplig sammanfattning}

Kemiska reaktioner styr det mesta i vardagen, allt ifrån att koka ett frukostägg till att köra bilen till jobbet. De flesta av vardagssysslorna har utformats och tagits fram utan att man ens har funderat över de underliggande kemiska processer som sker. Men många tekniska problem som vi nu står inför kräver att den underliggande processen förstås för att kunna lösas. Det traditionella sättet att utforska kemiska reaktioner har varit att göra empiriska experiment i laboratoriet. Men det är i många fall svårt och dyrt att efterlikna de miljöer och processer man vill studera i ett laboratorium. Det kan bero på dyra eller miljöfarliga kemikalier eller extrema miljöer t.ex. höga temperaturer. Ett alternativ eller komplement till det praktiska experimentet är därför att med hjälp av teoretiska modeller räkna ut hur en reaktion kommer uppträda. De teoretiska modellerna bygger på de stora vetenskapliga framsteg inom fysik som skedde under den första halvan av 1900-talet med framför allt Bohrs atommodell, Planck och senare Schrödingers och Heisenbergs utveckling av kvantmekaniken. Dessa teorier och modeller kunde sedan, med hjälp av de allt kraftfullare datorerna, användas för att modellera allt större system och processer. Mängder av algoritmer och program för att simulera molekylers interaktion med omvärlden används nu för att utforska processer och miljöer som tidigare var omöjliga att studera.

Mycket av dagens tekniska utmaningar går ut på att minska energikonsumtionen och utsläppen av växthusgaser. Detta samtidigt som användandet ökar av energikrävande produkter såsom elektronik, transporter och mat. Eftersom det i många av dagens produkter finns allt mer inbyggd elektronik så är det önskvärt med energieffektivisering av de transistorstrukturer som elektroniken består av. I dagens elektroniska kretsar används halvledarmaterialet kisel eftersom det är billigt och fungerar. Ett alternativ till kisel är kiselkarbid vilket skulle effektivisera kretsarna avsevärt i både storlek och energiåtgång. Problemet är att produktion av transistorstrukturer av kiselkarbid är dyrt och svårt att massproducera. I 
denna avhandling undersöks en av de vanligaste produktionsmetoderna, kemisk ångdeponering eller chemical vapor deposition (CVD), av kiselkarbid. I denna process så låter man en gasblandning flöda över en yta. Molekyler i gasen kommer att reagera med ytan och genom att reglera gassammansättningen, temperaturen, trycket och flödet så kan en tillväxt av kiselkarbid ske på ytan. Ytan byggs succesivt upp lager för lager tills den tjocklek som eftersträvas erhållits. För att kunna justera de parametrar som styr tillväxten på ett bra sätt så är det viktigt att förstå hur de kemiska reaktionerna mellan molekylerna i gasen och ytan sker. Dessa kemiska reaktioner studeras i detta arbete med hjälp av kvantkemiska simuleringar. På så sätt kan man undersöka olika typer av molekyler som experimentellt kan vara svåra, dyra eller farliga att testa. Det här arbetet visar att viktiga molekyler för tillväxten av kiselkarbid är kiselatomer, kiselklorid och kiselhydrid.

Ett annat aktuellt problem är den allt högre halten av växthusgaser i atmosfären där den mest omtalade är koldioxid. Det finns en tydlig koppling mellan global medeltemperatur och global koldioxidhalt, högre koldioxidhalt sammanfaller med högre medeltemperatur. Variationer i koldioxidhalten är inget nytt utan forskare har genom att t.ex. studera isprover från Antarktis slagit fast att nivån koldioxid varierar i cykler. Många forskare menar dock att vi nu har en koldioxidnivå som är högre, och ökar snabbare, än någonsin förr och att det är människan som genom förbränning av fossila bränslen står för denna enorma ökning. Man menar också att detta leder till radikalt ökad global medeltemperatur med allvarliga konsekvenser för många växter, djur och människor. Därför är det av intresse att försöka hindra att halten koldioxid i atmosfären ökar. En metod för att göra det är att omvandla koldioxiden till metanol, detta kan göras genom att samla upp koldioxid från fossil förbränning eller "skörda" koldioxid direkt från atmosfären. Metanolen kan sedan användas till bränsle som kan användas i förbränningsmotorer. Metanolen fungerar på så sätt som en återvinningsbar och miljömässigt hållbar energibärare. Problemen är att det kostar mycket energi att få reaktionen som omvandlar koldioxid och vatten till metanol att ske och att reaktioner som leder till andra, oönskade, produkter istället kan ske. För att minska energin som krävs för att aktivera reaktionen så kan en 
katalysator användas. Det kostar initialt energi att bryta de kemiska bindningar som de ingående molekylerna har, men detta kan göras mindre energikrävande genom att först bilda någonting annat som inte kräver lika mycket energi. Låt oss säga att vi har ämne A och B vilka tillsammans kan bilda $\mathrm{AB}$ men detta kräver stor aktiveringsenergi. Då kan man istället för att bilda $\mathrm{AB}$ direkt utnyttja ett nytt ämne $\mathrm{C}$ som katalysator. $\mathrm{A}$ och $\mathrm{C}$ kan då bilda $A C$ via en lägre energibarriär, för att sedan enklare kunna reagera med $\mathrm{B}$ och bilda $\mathrm{AB}$. Då gynnas bildandet av $\mathrm{AB}$ framför molekyler med okatalyserade reaktioner. Problemet är att hitta ett effektivt ämne $\mathrm{C}$ och gynnsamma yttre parametrar såsom temperatur, tryck och koncentrationer.

Eftersom reaktionerna sker på katalysatorns yta så är det fördelaktigt att ha så stor yta i förhållande till volym som möjligt, då det medför att fler reaktioner kan ske samtidig. Nanopartiklar har mycket stor yta i förhållande till volym och är därför intressanta att studera. Ett sätt att skapa nanopartiklar är genom att med hög energi sönderdela ett material till ett plasma, vilket $\mathrm{i}$ princip är ett moln av atomkärnor och elektroner. När detta moln sedan kyls ner bildas först små partiklar bestående ett par atomer vilka sedan växer till sig och bildar det vi kallar nanopartiklar, partiklar i storleksordningen 1-100 nm. I den tidiga tillväxtfasen för nanopartiklarna så är de elektriska fälten runt partiklarna av stor vikt för att förstå tillväxtprocessen. I avhandlingen undersöks hur de elektriska laddningarna beror på storleken av partiklarna och vilka elektriska fält som de ger upphov till.

I detta arbete undersöks också hur en katalysatorblandning bestående av zirkonium(IV)oxidpulver och kopparpulver påverkar metanolsyntesen. Flera möjliga reaktionsvägar där koldioxid och vätgas reagerar med zirkoniumoxid- och kopparytor presenteras. I ett exempel reagerar koldioxid med zirkoniumoxidytan och avges sedan som kolmonoxid för att i ett senare steg bilda metanol. I ett annat exempel reagerar den ytbundna koldioxiden med vätgas och efter omformeringar på ytan så bildas metanol, som därefter lämnar ytan. Genom att förstå de kemiska reaktionerna för $\mathrm{Cu} / \mathrm{ZrO} 2$ katalysatorn bättre blir det lättare att optimera processen. Den ökade kunskapen om vilka katalytiska egenskaper som är önskvärda för metanolsyntes ger även en bättre utgångspunkt för utvecklandet av nya bättre katalysatorer. 


\section{List of included publications}

I. Adsorption and surface diffusion of silicon growth species in silicon carbide chemical vapour deposition processes studied by quantumchemical computations

E. Kalered, H. Pedersen, E. Janzén and L. Ojamäe

Theor. Chem. Acc. 132, 1403 (2013)

II. Brominated Chemistry for Chemical Vapor Deposition of Electronic Grade SiC

M. Yazdanfar, Ö. Danielsson, E. Kalered, P. Sukkaew, O. Kordina, D. Nilsson, I.G. Ivanov, L. Ojamäe, E. Janzén, and H. Pedersen Chem. Mater. 27, 793-801 (2015)

III. Growth Mechanism of SiC Chemical Vapor Deposition: Adsorption and Surface Reactions of Active Si Species

P. Sukkaew, E. Kalered, E. Janzén, O. Kordina, Ö. Danielsson and L. Ojamäe

J. Phys. Chem. C 122, 648-661 (2018)

IV. On the work function and the charging of small $(\mathrm{r} \leq 5 \mathrm{~nm})$ nanoparticles in plasmas

E. Kalered, N. Brenning, I. Pilch, L. Caillault, T. Minéa and L. Ojamäe

Phys. Plasmas 24, 013702 (2017)

V. Conversion of $\mathrm{CO}_{2}$ to $\mathrm{CO}$ catalyzed by $\mathrm{ZrO}_{2}$ nanoparticles studied using quantum-chemical calculations

E. Kalered, E. Erdtman and L. Ojamäe

Submitted

VI. Theoretical and experimental study of IR spectra for $\mathrm{ZrO}_{2}(\mathrm{~s})$ and $\mathrm{Cu}(\mathrm{s})$ interacting with $\mathrm{CO}_{2}$ and $\mathrm{H}_{2}$

E. Kalered, P. Mäkie, P-O. Käll, M. Odén and L. Ojamäe In manuscript 


\section{My contribution to the papers}

Performed the quantum-chemical calculations, analyzed the data, and wrote most of the paper I, IV, V, VI. Performed the quantum-chemical calculations, participated in the scientific discussion, designed figures and wrote parts of the paper II and III.

\section{Related, not included publications}

I. Nucleation of titanium nanoparticles in an oxygen-starved environment, II: Theory

R. Gunnarsson, N. Brenning, L. Ojamäe, E. Kalered, M. A. Raadu and U. Helmersson

Submitted

II. Synthesis of $\mathrm{CH}_{3} \mathrm{OH}$ by $\mathrm{CO}_{2}$ hydrogenation over a $\mathrm{Cu} / \mathrm{ZrO}_{2}$ catalyst studied by quantum-chemical computations

E. Kalered, E. Erdtman, P-O. Käll, M. Odén and L. Ojamäe In manuscript 


\section{Abbreviations}

ACT Activated complex theory

CVD Chemical vapor deposition

DFT Density functional theory

EFE Electron field emission

FTIR Fourier transform infrared radiation

IR Infrared radiation

GGA General gradient approximation

GTO Gaussian-type orbitals

HF Hartree-Fock

HOMO Highest occupied molecular orbital

LDA Local density approximation

LUMO Lowest unoccupied molecular orbital

MCSCF Multicinfiguration Self-consistent-field

NP Nanoparticle

SCF Self-consistent-field

STO Slater-type orbitals

STQN Synchronous transit-guided quasi-Newton

TS Transition state

TIE Thermionic electron emission

TST Transition state theory

QST Quadratic synchronous transit 


\section{Acknowledgements}

I would like to first thank my supervisor Prof. Lars Ojamäe for his great help and guidance during my time at Linköping University. Secondly I would like to acknowledge the support from my co-supervisor Assoc. Prof. Henrik Pedersen and Prof. Per-Olov Käll. Thanks for the introduction to the field of chemistry. This work would not be possible without your guidance and encouragement from all of you.

I would also like to thanks Maria, Edvin and all the other colleagues at the chemistry and physic department for interesting discussions. Thanks to the great people in the Agora Materiae Graduate School. A special thanks to all my friends in the orienteering sphere at LiU, Peter, Johan, Erik, Per, Micke and all other for interesting discussions about other things beside work.

I would like to thank my Mom and Dad and the rest of my family for being there. I would also like to thank my biggest fan, first cousin Jenny. I doubt I will deliver that banquette in Stockholm you wished for but at least you get a mention here. 


\section{Introduction}

\subsection{Chemical Reactions}

Chemical reactions are a central part in many technological processes and in the everyday life. All things in nature are built up by small particles, where classically the atom is the smallest part. There are a wide range of structures ranging from small molecules with a few atoms, like the water molecule, to larger molecules like proteins with hundreds or thousands of atoms, and all the way up to very large structures such as solid metals with $\sim 10^{23}$ atoms. The atoms themselves are built up by a positive charged core, the nuclei, and a surrounding cloud of negatively charged electrons. Interactions between all physical things boils down to interactions between these electron clouds. A chemical reaction is defined as a transition between two structures, which in a simple case can be a gas phase reaction where two molecules comes together creating a new set of molecules, e.g. two water molecules creating hydrogen and oxygen molecules, $2 \mathrm{H}_{2} \mathrm{O}(g) \rightarrow 2 \mathrm{H}_{2}(g)+\mathrm{O}_{2}(g)$, see Figure 1. Other examples are surface reactions where small molecules adsorbs on the surface or rearrangements of surface structures.
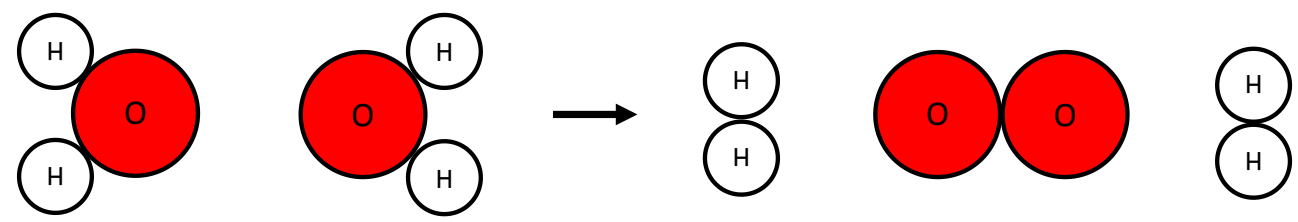

Figure 1. A schematic gas phase reaction where two water molecules reacts and form two hydrogen molecules and one oxygen molecule.

This thesis focus on reactions taking place at a surface, but also in some cases consider gas phase reactions. Important properties when studying chemical reactions are the bond strengths, i.e. the amount of energy required to break a bond and the amount of energy released by creating a bond. For example, when a certain product is desired from a chemical process these bond strengths can be modified by the environment to make it easier or harder to break the bonds, and, by doing so, steer the reactions towards the desired 
product. To be able to predict how the environment should be changed in order to improve the process, information about the energy landscape for the chemical system is desired. These energies can be calculated using quantum chemical ab initio calculations, offering the possibility to avoid experimental tests in situ, which can be difficult or even impossible to perform.

\subsection{Silicon Carbide}

Silicon carbide ( $\mathrm{SiC}$ ) is a semiconductor and an extremely hard material with a hardness of 9.3 on the Mohs scale (where 1 corresponds to talc and 10 to diamond ${ }^{1}$. Due to its extreme hardness it is often used as a cutting tool in mechanical applications. Silicon carbide appear in over 250 different polytypes ${ }^{2,3}$ which are usually named according to the scheme proposed by Ramsdell ${ }^{4}$. The naming scheme consists of a number and a letter, where the letter $(\mathrm{C}, \mathrm{H}$ and $\mathrm{R})$ indicates the crystal structures cubic, hexagonal and rhombohedral. The number indicates the number of layers in the unit cell. Each layer can be placed in three different positions A, B and C, for example a crystal structure built up by repeating $\mathrm{ABAB} \ldots$ is therefore known as a 2H-SiC.
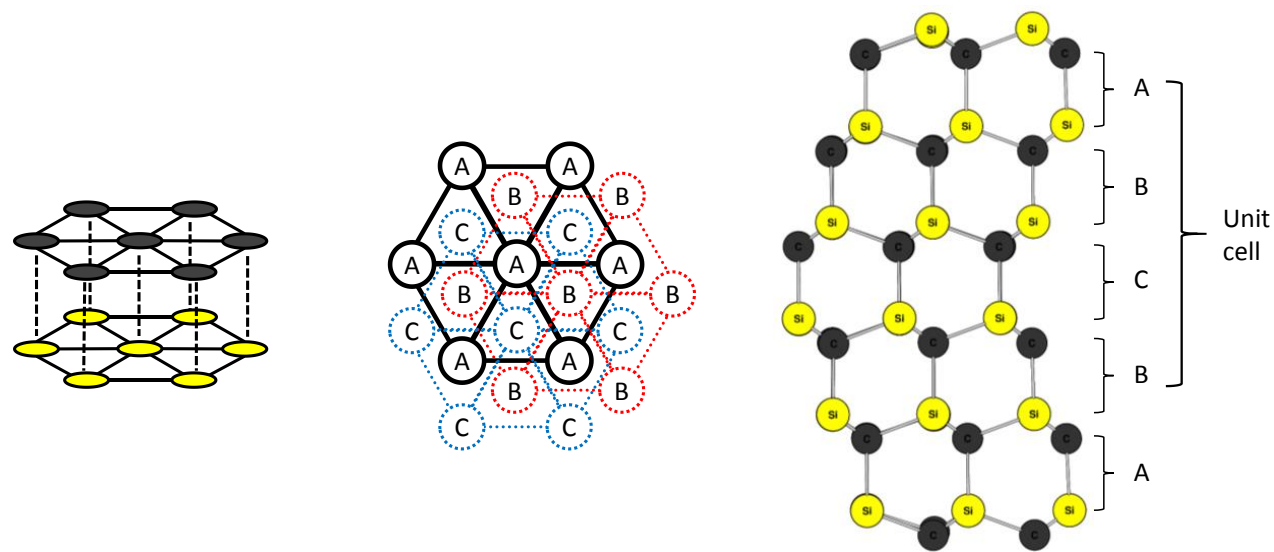

Figure 2. To the left is a hexagonal silicon carbide layer. In the middle is a representation of the three different layer positions possible. To the right is a $4 \mathrm{H}-$ $\mathrm{SiC}$ structure which have 4 layers in its unit cell, ABCB.

Silicon is the classic semiconductor used for most of today's basic electronic applications. SiC has a range of superior properties compared to the conventional silicon, which could greatly enhance many of today's 
electronic devises. The $\mathrm{SiC}$ properties are especially suitable for high power electronic devises due to the wide band gap, high electric breakdown field and a high maximum operation temperature ${ }^{5-8}$. For comparison with other common semiconductors see Table 1.

Table 1. Electrophysical properties for silicon, and for wide bandgap semiconductors.

\begin{tabular}{|l|r|r|r|r|r|r|r|}
\hline Properties & Si & $\begin{array}{c}\text { 4H- } \\
\text { SiC }\end{array}$ & $\begin{array}{c}\text { 6H- } \\
\text { SiC }\end{array}$ & $\begin{array}{c}\text { 3C- } \\
\text { SiC }\end{array}$ & GaN & AlN & Diamond \\
\hline $\mathbf{E}_{\mathbf{g}}(\mathrm{eV})^{9-11}$ & 1.1 & 3.2 & 3.0 & 2.3 & 3.4 & 6.2 & 5.5 \\
\hline $\mathbf{T}_{\mathbf{o p}}(\mathrm{K})^{10,11}$ & 410 & 1230 & 1200 & 840 & 1250 & 2100 & 2100 \\
\hline $\mathbf{E}_{\mathbf{c}}\left(\mathrm{MV} \mathrm{cm}^{-1}\right)^{9,10,12}$ & 0.3 & 3 & 2.5 & 1 & 5 & 1.5 & 10 \\
\hline $\boldsymbol{\lambda}\left(\mathrm{W} \mathrm{cm}^{-1} \mathrm{~K}^{-1}\right)^{9-11}$ & 1.3 & $5-7$ & $5-7$ & $3-5$ & 1.3 & 2 & 20 \\
\hline $\boldsymbol{\varepsilon}_{\mathbf{r}}^{9,10}$ & 12 & 10 & 10 & 10 & 9 & 9 & 6 \\
\hline $\boldsymbol{\mu}_{\mathbf{e}}\left(\mathrm{cm}^{2} \mathrm{~V}^{-1} \mathrm{~s}^{-1}\right)^{9-12}$ & 1400 & 1000 & 400 & 900 & 1200 & 300 & 2000 \\
\hline $\boldsymbol{\mu}_{\mathbf{h}}\left(\mathrm{cm}^{2} \mathrm{~V}^{-1} \mathrm{~s}^{-1}\right)^{9-12}$ & 500 & 100 & 100 & 50 & 500 & 15 & 1600 \\
\hline
\end{tabular}

Note: $\mathbf{E}_{\mathbf{g}}-$ band gap, $\mathbf{T}_{\mathbf{o p}}-$ maximum operation temperature, $\mathbf{E}_{\mathbf{c}}-$ critical breakdown field, $\boldsymbol{\lambda}$-thermal conductivity, $\boldsymbol{\varepsilon}_{\mathbf{r}}-$ relative dielectric constant, $\boldsymbol{\mu}_{\mathbf{e}}-$ electron mobility, $\boldsymbol{\mu}_{\mathbf{h}}$ - hole mobility.

The $4 \mathrm{H}-\mathrm{SiC}$ is currently the most common of the silicon carbide polytypes used in electronic applications and is therefore the chosen polytype investigated in this thesis ${ }^{6}$.

\subsection{CVD of Silicon Carbide}

In order to optimize the electronic properties of $4 \mathrm{H}-\mathrm{SiC}$ a high crystal purity is desired which can be achieved by growing epitaxial layers of silicon carbide. The production method commonly used for manufacturing epitaxial layer of silicon carbide is the Chemical Vapor Deposition (CVD) process ${ }^{13}$. In CVD of $\mathrm{SiC}$ epitaxial layers, a substrate of $4 \mathrm{H}-\mathrm{SiC}$ is placed in a chamber heated to around $1600{ }^{\circ} \mathrm{C}$ and with an internal pressure in the order of 100 mbar ${ }^{13}$. Then a carrier gas, often hydrogen, is flown through the chamber. In the carrier gas a mixture of precursors containing silicon and carbon atoms is added, see Figure 3. 


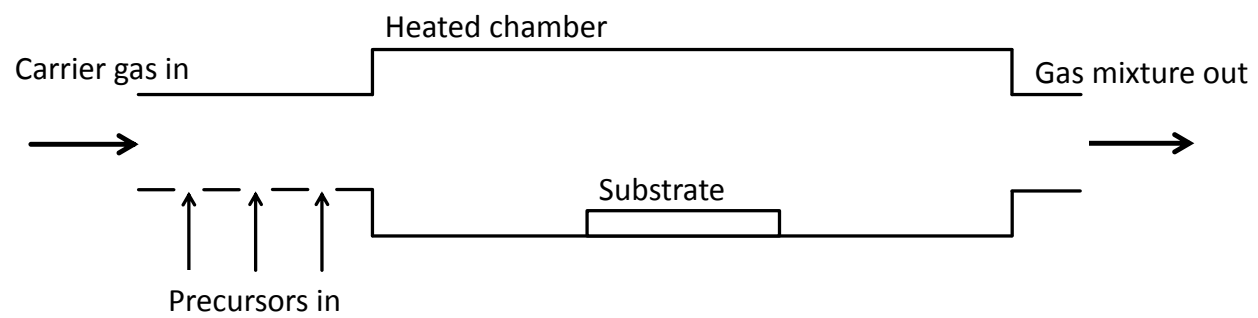

Figure 3. A schematic drawing of a CVD-reactor.

After a series of chemical reactions in the gas phase, silicon and carbon gets disposed on the substrate where surface reactions take place, leading to a growth of epitaxial layers of $\mathrm{SiC}$ on the substrate, see Figure 4.

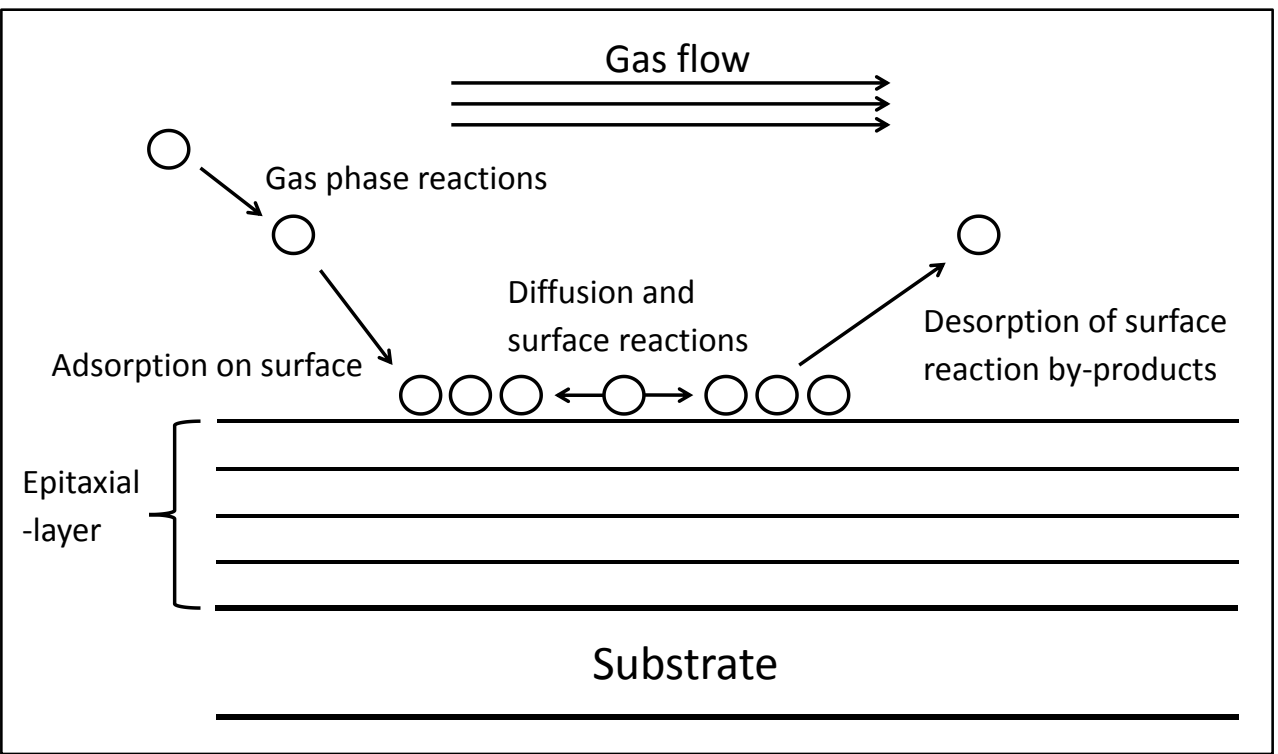

Figure 4. A schematic drawing of the CVD-process at the surface.

To decrease the costs of producing $\mathrm{SiC}$ the growth rate of the epitaxial layers of $\mathrm{SiC}$ needs to be increased, whilst maintaining good crystal quality. This is done by either increasing the number of silicon and carbon atoms passing through the chamber per time unit, or by changing the chemical mixture to obtain more reactive molecules. However this might result in formation of aggregates, mainly silicon droplets, which in contact with the surface causes defects to be formed, making the epitaxial layer unusable for electric devices. 
To avoid these silicon droplets being formed, one idea is to introduce an element to the gas mixture that binds stronger to silicon than silicon itself. Good candidates are the halogen elements of which chlorine is the most commonly used. Chlorinated compounds are also available with high purity. The CVD method where chloride is added to the gas mixture is called chloride-based CVD and it has been shown to greatly increase the growth speed and decrease the needed chamber temperature without reducing the quality of the product ${ }^{13,14}$.

Typical precursors are silane $\left(\mathrm{SiH}_{4}\right)$ and light hydrocarbons such as ethylene $\left(\mathrm{C}_{2} \mathrm{H}_{4}\right)$ or propane $\left(\mathrm{C}_{3} \mathrm{H}_{8}\right)$. The inclusion of chlorine can for example be facilitated by the use of hydrogen chloride $(\mathrm{HCl})$ or trichlorosilane $\left(\mathrm{CH}_{3} \mathrm{SiCl}_{3}\right)$ as a precursor, and the inclusion of bromine can be achieved by the use of for example hydrogen bromide $(\mathrm{HBr})$ or tribromosilane $\left(\mathrm{CH}_{3} \mathrm{SiBr}_{3}\right)^{13-15}$. During the gas phase chemistry the precursor molecules are transformed into reactive gaseous species which will interact with the surface. Typical species reacting with the surface have from thermophysical studies been suggested to be $\mathrm{SiH}_{2}$ and $\mathrm{SiCl}_{2}{ }^{16-18}$.

\subsection{Methanol synthesis}

During the last one and a half century the fossil fuels have been the prime energy source used for transportation, heating and electricity generation. This has been a key factor for human development but the use of fossil fuels also correlates to an increase of the atmospheric carbon dioxide concentration. From beginning of the industrial revolution until today the atmospheric $\mathrm{CO}_{2}$ concentration has increased from $280 \mathrm{ppm}$ to more than $400 \mathrm{ppm}^{19}$. This increase correlates with enhancement of the global mean temperature which many scientists argue will have negative effects for ecological systems and could potentially even threaten the human species. It is also assumed that the oil deposits eventually will be depleted, i.e. the cost of exploration of new or old oil wells will at some point exceed the market value of the product ${ }^{20,21}$, hence alternatives to fossil fuels are desired. Replacement by renewable energy sources like solar and wind, or by reliable and high-capacity but carbon free sources like nuclear, would thus be desired. 
One way to reduce the $\mathrm{CO}_{2}$ levels in the atmosphere, or at least to slow down the increasing $\mathrm{CO}_{2}$ levels, is to capture carbon dioxide from the atmosphere or at the sites (e.g. flume gases at power plants and volcanic exhausts) where it is being produced. In carbon sequestration ${ }^{22}$ carbon dioxide is stored in carbon sinks such as saline aquifers or reservoirs after carbon capture. At the same time, carbon-containing liquid fuels like heavier hydrocarbons esters and alcohols are space efficient with high energy density, and can be used in existing energy distribution infrastructure (e.g. gas stations). A possibility is to recycle the captured $\mathrm{CO}_{2}$ and turn it (again) into a fuel. This fuel would then be used without a net increase of atmospheric $\mathrm{CO}_{2}$.
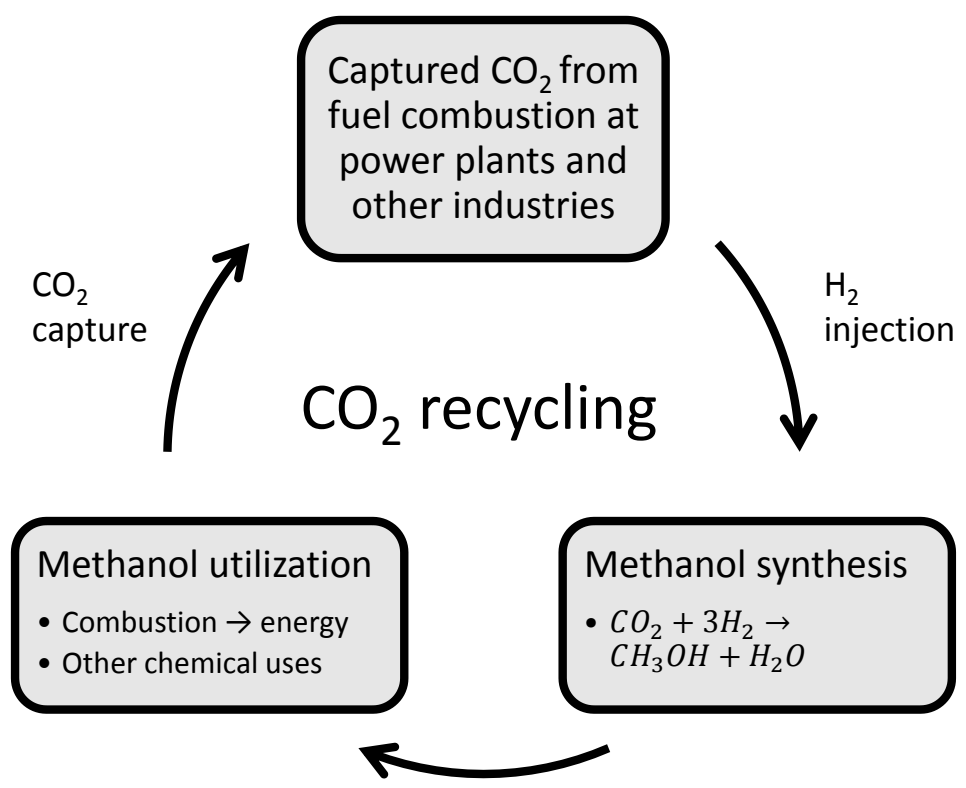

Purification

Figure 5. $\mathrm{CO}_{2}$ recycling scheme.

A route is to synthesize methanol from carbon dioxide and hydrogen gas. By doing so a portion of the atmospheric carbon dioxide will be bounded to the methanol cycle and makes methanol a renewable and sustainable energy carrier. Methanol would not be an energy source, since energy (preferably renewable) is needed as input (i.e. via the hydrogen production), but a 
convenient and net carbon-free energy carrier that can be used in ordinary combustion engines or fuel cell electric engines.

The simplest gas phase reaction to synthesize methanol is

$$
\mathrm{CO}_{2}(\mathrm{~g})+3 \mathrm{H}_{2}(\mathrm{~g}) \rightarrow \mathrm{CH}_{3} \mathrm{OH}(\mathrm{g})+\mathrm{H}_{2} \mathrm{O}(\mathrm{g})
$$

which is exothermic with a $\Delta_{\mathrm{r}} \mathrm{H}^{0}$ of $-49.5 \mathrm{~kJ} \mathrm{~mol}^{-123}$, but has a high activation energy ${ }^{24}$, making the process slow. It is also very non-specific in that other product species like methane dominate at thermodynamic equilibrium. To reduce the required activation energy and increase the selectivity towards methanol a catalyst is usually introduced.

\subsection{Heterogeneous catalysis}

There are two main types of catalysis, the homogeneous and the heterogeneous. In homogeneous catalysis the reactant and catalyst is of the same phase, whereas in the heterogeneous catalysis the phase of the reactant differs from that of the catalyst. Normally this for example implies that the reactants are in gas phase and the catalysts are in liquid or solid phase but it can also refer to immiscible liquids, e.g. water and oil. By far, the most common heterogeneous catalysts used in practical applications are solids where the reactants are smaller gas molecules or liquids ${ }^{25}$. An essential step in these processes is the adsorption of the gas molecules on the solid catalyst surface.

There are essentially two types of adsorptions, physisorption and chemisorption. Physisorption is typically van der Waals interactions with weak interaction energies between the molecule and surface in the order of a few $\mathrm{kJ} \mathrm{mol}^{-1}$. Chemisorption is a stronger interaction which might involve bond breaking and results in sharing of electrons between the molecule and surface atoms resulting in a bond strength in the order of hundreds $\mathrm{kJ} \mathrm{mol}^{-1}$. Two main catalytic adsorption processes are the Langmuir-Hinshelwood mechanism and the Rideal-Eley mechanism ${ }^{26}$. In the LangmuirHinshelwood mechanism two reactants A and B adsorbs to the surface, creating the adsorbed species AS and BS. The adsorbed molecules then meet each other on the surface through diffusion and react to create the product $P$.

$$
\left\{\begin{array}{l}
\mathrm{A}+\mathrm{S} \rightarrow \mathrm{AS} \\
\mathrm{B}+\mathrm{S} \rightarrow \mathrm{BS}
\end{array} \Rightarrow \mathrm{AS}+\mathrm{BS} \rightarrow \mathrm{P}\right.
$$


In the Rideal-Eley mechanism reactant A adsorbs to the surface, creating AS where upon reactant $\mathrm{B}$ binds directly to AS creating the product $\mathrm{P}$.

$$
\mathrm{A}+\mathrm{S} \rightarrow \mathrm{AS} \Rightarrow \mathrm{AS}+\mathrm{B} \rightarrow \mathrm{P}
$$

Reaction paths including both these processes arising from the ideas of Arena et al. are studied in this thesis, see Figure $6^{24,27}$.

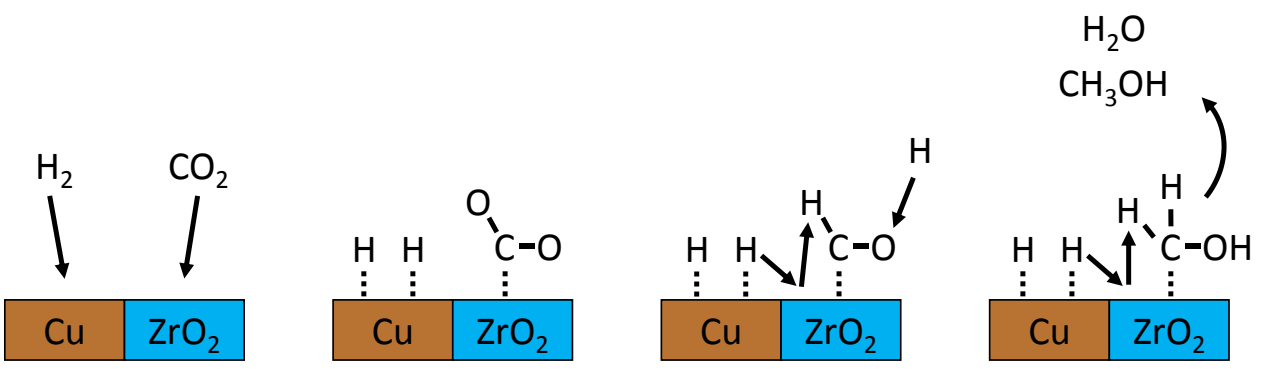

Figure 6. Proposed reaction pathway for the formation of methanol from $\mathrm{CO}_{2}$ and $\mathrm{H}_{2}$ with $\mathrm{Cu} / \mathrm{ZrO}_{2}$ catalyst ${ }^{24,27}$.

\subsection{Methanol synthesis by heterogeneous catalysis}

To reduce the high activation energy for the methanol reaction and to reduce the amount of by-products created a highly selective catalyst is needed ${ }^{23,28}$. Many different metal-based catalysts have been examined for the synthesis of methanol and copper is the typical choice as a general active catalyst component mixed with different modifiers (Zr, Zn, Si, Al etc.) ${ }^{29-31}$. Zirconia has been considered as a good supporter to copper due to its high stability in reducing or oxidizing environments ${ }^{30,32,33} \cdot \mathrm{ZrO}_{2}$ has also been shown to enhance the catalytic activity and selectivity toward methanol of the copper catalyst ${ }^{30,34-37}$. Furthermore, the performance of the catalyst is influenced by the crystal types of zirconia. The monoclinic structure has been shown to be 4.5 times more active than the tetragonal structure, possible due to the higher concentration of adsorbed active intermediates (i.e., $\mathrm{HCOO}$ and $\mathrm{CH}_{3} \mathrm{O}$ ) ${ }^{38}$. Other promising oxides are $\mathrm{ZnO}$, and $\mathrm{Ga}_{2} \mathrm{O}_{3}{ }^{32,36,37}$. In this thesis a mixture of copper and $\mathrm{ZrO}_{2}$ nanoparticles has been studied. 


\section{Computational methods}

\subsection{Electron structure theory}

Quantum mechanics is used to calculate properties such as energy, charge, dipole moment etc. for a complex system of particles. To obtain the properties for a specific system of particles the time-independent Schrödinger equation for the system needs to be solved and the eigenvalues and eigenfunctions need to be found. The complete equation can be written in the compact form as ${ }^{39}$ :

$$
\widehat{H}_{\text {tot }} \Psi_{\text {tot }}=E_{\text {tot }} \Psi_{\text {tot }}
$$

Where $\widehat{H}_{\text {tot }}$ is the Hamiltonian operator containing the energy operators for all particles, $\Psi_{\text {tot }}$ is the total many-body wavefunction and $E_{\text {tot }}$ is the total energy for the system. This equation can only be solved analytically for systems with very few degrees of freedom, typically small systems e.g. particle in a box and the hydrogen atom. Therefore various approximations is required in order to facilitate computations for realistic systems.

Due to the fact that the nucleus is much heavier than an electron the so called Born-Oppenheimer approximation is invoked ${ }^{40}$. The nuclei is considered to be stationary compared to the electrons and the wavefunction $\Psi_{\text {tot }}$ can therefore be separated into an electronic part, $\Psi_{e}$, and a nuclear part, $\Psi_{n}$. This simplifies into the electronic Shrödinger equation which only depends parametrically on the positions of the nuclei.

$$
\left(\widehat{H}_{e}+V_{n n}\right) \Psi_{e}=E_{e} \Psi_{e}
$$

$\widehat{H}_{e}$ contains three parts, one corresponding to the kinetic energy operator $\widehat{T}_{e}$, one for the nucleus-electron attraction $V_{n e}$ and one corresponding to the electron-electron repulsion $V_{e e}$. This gives, expressed in atomic units $(\hbar=$ $\left.m_{e}=\frac{1}{4 \pi \varepsilon_{0}}=e=1\right)$ :

$$
\left(\widehat{T}_{e}+V_{n e}+V_{e e}+V_{n n}\right) \Psi_{e}=E_{e} \Psi_{e}
$$




$$
\begin{aligned}
& \widehat{T}_{e}=-\frac{1}{2} \sum_{i}^{N_{e}} \nabla_{i}^{2} \\
& V_{n e}=-\sum_{a}^{N_{n}} \sum_{i}^{N_{e}} \frac{Z_{a}}{\left|\boldsymbol{R}_{a}-\boldsymbol{r}_{i}\right|} \\
& V_{e e}=\sum_{i}^{N_{e}} \sum_{j>i}^{N_{e}} \frac{1}{\left|\boldsymbol{r}_{i}-\boldsymbol{r}_{j}\right|} \\
& V_{n n}=\sum_{a}^{N_{n}} \sum_{b>a}^{N_{n}} \frac{z_{a} z_{b}}{\left|\boldsymbol{R}_{a}-\boldsymbol{R}_{b}\right|}
\end{aligned}
$$

where $N_{e}$ denotes the total number of electrons, $\nabla_{i}^{2}$ is the Laplace operator acting on electron $i, N_{n}$ is the total number of nuclei, $Z_{a}$ is the atomic number of nuclei $a, \boldsymbol{R}_{a}$ and $\boldsymbol{r}_{i}$ denotes the coordinates for the nuclei $a$ and electron $i$. This many-body equation is still difficult to solve therefore further approximations are needed and one common method is the Hartree-Fock approach. Another approach is the electron density theory where the manybody wavefunctions is replaced with the electron density and thereby reducing the complexity down to only three dimensions.

\subsection{Hartree-Fock}

The aim of the Hartree-Fock method is to reduce the many-electron problem to a set of one-electron problems where each electron's interaction with the other electrons is treated in an average way. The many-electron wavefunction is approximated by a combination of one-electron orbitals, $\Phi_{i}$. To satisfy the Pauli principle ${ }^{41}$ this combinations of molecular orbitals can be written as a Slater determinant ${ }^{42}$ :

$$
\Psi_{e}=\frac{1}{\sqrt{N_{e} !}} \operatorname{det}\left(\Phi_{1}, \Phi_{2}, \Phi_{3}, \ldots, \Phi_{N_{e}}\right)
$$

By applying the variation principle it turns out that the one-electron spin orbitals need to satisfy a set of equations known as the Hartree-Fock equations $^{43}$ :

$$
f_{1} \Phi_{i}\left(\boldsymbol{x}_{1}\right)=\varepsilon_{i} \Phi_{i}\left(\boldsymbol{x}_{1}\right)
$$

$f_{1}$ is the Fock operator, the label "1", denoting electron 1, is used to distinguish the two electrons appearing when applying the Fock operator. $\Phi_{i}$ are the different one-electron orbitals, $\boldsymbol{x}_{1}$ is the spatial and spin coordinate for electron 1 and $\varepsilon_{i}$ is the energy for the corresponding orbital. The Fock 
operator consists of terms that describe the kinetic energy, $\widehat{T}_{1}$, for electron 1 in $\Phi_{i}$, the potential energy, $V_{1 n}$, between the electron 1 in $\Phi_{i}$ and the nuclei in the system, the Coulomb interactions $J_{i j}$ and the effects of spin correlation $K_{i j}$ between the electron 1 in $\Phi_{i}$ and electron 2 in the other orbitals $\Phi_{j \neq i}$ 44,45 .

$$
f_{1}=\widehat{T}_{1}+V_{n, 1}+\sum_{j \neq i}\left(J_{i j}-K_{i j}\right)
$$

where

$$
\begin{aligned}
& \widehat{T}_{1}=-\frac{1}{2} \nabla_{1}^{2} \\
& V_{n, 1}=-\sum_{a}^{N_{n}} \frac{z_{a}}{\left|\boldsymbol{R}_{a}-\boldsymbol{r}_{1}\right|} \\
& J_{i j}=\int\left|\Phi_{j}\left(\boldsymbol{x}_{2}\right)\right|^{2} \frac{1}{\left|\boldsymbol{r}_{2}-\boldsymbol{r}_{1}\right|} d \boldsymbol{x}_{2} \\
& K_{i j}=\int \Phi_{j}^{*}\left(\boldsymbol{x}_{2}\right) \Phi_{i}\left(\boldsymbol{x}_{2}\right) \frac{1}{\left|\boldsymbol{r}_{2}-\boldsymbol{r}_{1}\right|} d \boldsymbol{x}_{2}
\end{aligned}
$$

As can be seen in equations (6c) and (6d) the Fock operator involves the initially unknown orbitals (eigenfunctions) making the Hartree-Fock equation a nonlinear eigenvalue problem. Thus the equation has to be solved iteratively by making an initial guess for the orbitals, $\Phi_{i}$. The Hartree-Fock equations is then solved and a new set of orbitals is obtained to be used in the Fock operator the next iteration. The iteration is repeated until selfconsistency is reached. This procedure is called the self-consistent-field (SCF) method.

A common restriction to simplify the calculation further is to, when possible, define the orbitals as restricted, i.e. electrons that appear in pairs with opposite spin share a common spatial orbital. This is also known as a closed shell configuration. The opposite situation where each electron has its own spatial orbital is known as the unrestricted or open shell configuration. In the closed shell configuration the orbitals can be separated into a spatial part and a spin part.

$$
\Phi_{i}(\boldsymbol{x})=\left\{\begin{array}{l}
\psi_{j}(\boldsymbol{r}) \alpha(\omega) \\
\psi_{j}(\boldsymbol{r}) \beta(\omega)
\end{array}\right.
$$

This reduces the general Hartree-Fock equation to the spatial integrodifferential equation 


$$
f\left(\boldsymbol{r}_{1}\right) \psi_{i}\left(\boldsymbol{r}_{1}\right)=\varepsilon_{i} \psi_{i}\left(\boldsymbol{r}_{1}\right)
$$

This equation can be solved by replacing the spatial orbitals $\psi_{i}$ with a linear combination of atomic orbitals $\varphi_{j}$ :

$$
\psi_{i}=\sum_{j=0}^{N_{a}} c_{j i} \varphi_{j}
$$

where $N_{a}$ is the number of atomic orbitals used to describe the one-electron orbitals. The set of atom-like orbitals, $\varphi_{i}$, is referred to as a basis set. The set of equations can now be expressed in matrix form and is known as the Roothan equations ${ }^{46}$.

$$
F \boldsymbol{c}=\boldsymbol{S c \varepsilon}
$$

where $\boldsymbol{F}$ is the Fock matrix, $\boldsymbol{c}$ is a matrix built up by the coefficients $c_{i m}, \boldsymbol{S}$ is a matrix consisting of overlap integrals and $\boldsymbol{\varepsilon}$ is formed from the molecular orbital energies $\varepsilon_{i}$. The task now boils down to find the coefficients in $\boldsymbol{c}$ during the SCF iteration.

The drawback of the Hartree-Fock approach is that the electron correlation is not properly described since the explicit electron-electron interaction is replaced by an average interaction. A good description of the electron correlation is essential when calculating molecular properties and therefore many improvements to the Hartree-Fock theory have been made, e.g. configuration interaction ${ }^{47,48}$, Møller-Plesset perturbation theory 49 coupled-cluster theory ${ }^{50,51}$. and multiconfiguration SCF (MCSCF) theory ${ }^{47}$.

\subsection{Density Functional Theory (DFT)}

The electron correlation additions needed to compliment the Hartree-Fock method in order to obtain molecular properties in agreement with experiments are often very time-consuming. This is the main reason for the development of the DFT method, which can treat the electron correlation at a much lower computational cost. The method is based on the ideas suggested by Thomas ${ }^{52}$ and Fermi ${ }^{53}$ where the electron density $\rho(\boldsymbol{r})$ replaces the electronic wavefunction $\Psi_{e}$. The theory is further developed by the theorem of Hohenberg and Kohn ${ }^{54}$ which states that all ground state molecular properties can be obtained via functionals of the ground state electron density function $\rho_{0}(\boldsymbol{r})$ for any given external potential $v_{\text {ext }}(\boldsymbol{r})$. The 
exact many-body energy, including all effects beyond the Hartree-Fock approximation, is given by:

$$
E[\rho(\boldsymbol{r})]=F[\rho(\boldsymbol{r})]+\int v_{\text {ext }}(\boldsymbol{r}) \rho(\boldsymbol{r}) d \boldsymbol{r}
$$

where $F$ is the universal functional containing kinetic and electron-electron interaction energies of the system. Hohenberg and Kohn also showed that the ground-state energy and ground-state electron density is obtained by minimizing $E$ in equation 11 with respect to variations in $\rho(\boldsymbol{r})$. The standard approach to solve the minimization problem is through the Kohn-Sham equations ${ }^{55}$. The functional $F$ can be devided into three parts, the KohnSham (also referred to as the single-particle) kinetic energy $T_{S}$ for a system of non-interacting electrons, the classical Coulomb energy (also referred to as the Hartree energy) $E_{H}$ and the exchange-correlation factor $E_{X C}$. All nonclassical effects of exchange and correlation and the portion of the kinetic energy not included in the Kohn-Sham kinetic energy is collected in the exchange-correlation factor.

$$
F[\rho(\boldsymbol{r})]=T_{S}[\rho(\boldsymbol{r})]+E_{H}[\rho(\boldsymbol{r})]+E_{X C}[\rho(\boldsymbol{r})]
$$

By expressing the electron density as a sum of one-particle eigenfunctions (also known as Kohn-Sham orbitals, $\psi_{k}(\boldsymbol{r})$ )

$$
\rho(\boldsymbol{r})=\sum_{k=1}^{N_{e}}\left|\psi_{k}(\boldsymbol{r})\right|^{2}
$$

the Kohn-Sham kinetic energy term can be written as

$$
T_{s}[\rho(\boldsymbol{r})]=\sum_{k=1}^{N_{e}} \int \frac{1}{2}\left|\nabla \psi_{k}(\boldsymbol{r})\right|^{2} d \boldsymbol{r}
$$

The energy minimization problem for equation (11) can now be rewritten as a set of one-electron equations with a Hamiltonian consisting of the KohnSham kinetic energy term and an effective one-body potential.

$$
\left(-\frac{1}{2} \nabla^{2}+v_{e f f}(\boldsymbol{r})\right) \psi_{k}(\boldsymbol{r})=\varepsilon_{k} \psi_{k}(\boldsymbol{r})
$$

where

$$
v_{e f f}(\boldsymbol{r})=v_{e x t}(\boldsymbol{r})+v_{H}(\boldsymbol{r})+v_{x c}(\boldsymbol{r})
$$

and

$$
\begin{aligned}
& v_{e x t}(\boldsymbol{r})=-\sum_{a}^{N_{n}} \frac{z_{a}}{\left|\boldsymbol{R}_{a}-\boldsymbol{r}_{1}\right|} \\
& v_{H}(\boldsymbol{r})=\int \frac{\rho\left(\boldsymbol{r}^{\prime}\right)}{\left|\boldsymbol{r}-\boldsymbol{r}^{\prime}\right|} d \boldsymbol{r}^{\prime}
\end{aligned}
$$




$$
v_{x c}(\boldsymbol{r})=\frac{\partial E_{X C}[\rho(\boldsymbol{r})]}{\partial \rho(\boldsymbol{r})}
$$

The set of equations is similar to the Hartree-Fock equations (5) with the Hamiltonian depending on the solution. It is therefore solved using the same method, the self-consistent-field (SCF) procedure. The calculations is intrinsically simpler in the Kohn-Sham procedure compared to in the Hartree-Fock approach because the effective potential $v_{\text {eff }}$ is local, and only act at the wavefunction in the point $\boldsymbol{r}$. Nevertheless the exchange correlation potential $v_{x c}$ has, in principal, a nonlocal electron density dependence.

The obstacle that remains is to find the explicit form of the exact exchange correlation functional $E_{X C}$, which, if found, would result in an exact theory. But the explicit form is not known, hence the accuracy of the Kohn-Sham procedure depends on the chosen approximation to the exchange correlation functional. The simplest approximation is the local density approximation (LDA), in which, the electron density is treated as homogenous and is calculated as

$$
E_{X C}[\rho(\boldsymbol{r})] \approx E_{X C}^{L D A}[\rho(\boldsymbol{r})]=\int \rho(\boldsymbol{r}) \varepsilon_{X C}[\rho(\boldsymbol{r})] d \boldsymbol{r}
$$

where $\varepsilon_{X C}$ is the exchange correlation energy per particle at a specific point, $\boldsymbol{r}$, for a spatially uniform electron gas. This approximation makes the $v_{\text {eff }}$ in equation (15) local, both in the sense that it acts only on $\psi_{k}(\boldsymbol{r})$ at $\boldsymbol{r}$, and also in the sense that it depends only on the density at $\boldsymbol{r}$. This approximation is most useful for systems where the electron density is close to uniform, e.g. bulk metals. A typical consequence arising from the LDA approach is overestimation of binding energies ${ }^{56}$. To improve the energy calculation the more advanced general gradient approximation (GGA) is used ${ }^{57-59}$. In the GGA both the density and its gradient is used and has the general form:

$$
E_{X C}[\rho(\boldsymbol{r})] \approx E_{X C}^{G G A}[\rho(\boldsymbol{r})]=\int \rho(\boldsymbol{r}) f[\rho(\boldsymbol{r}), \nabla \rho(\boldsymbol{r})] d \boldsymbol{r}
$$

where $f$ is a general function. Since the GGA functional takes the gradient of the electron density in consideration it is more suitable to use for molecular systems which have a more varying electron density.

Another way to improve the DFT method is to use the Kohn-Sham orbitals to calculate the exact Hartree-Fock exchange energy and then include this in addition to exchange and correlations from pure DFT 
functionals. This approach is known as a hybrid functional and has the general form

$$
E_{X C}^{H y b r i d}=a E_{X}^{H F}+(1-a) E_{X}^{D F T}+E_{C}^{D F T}
$$

One of the most popular hybrid functionals is the B3LYP functional ${ }^{60}$ which is used for the majority of the calculations in this thesis. It consists of a mixture of LDA, GGA and HF terms.

\subsection{Basis set}

The task in both Hartree-Fock and DFT theory is to iteratively find eigenfunctions (also referred to as wavefunctions or molecular orbitals) through the SCF method. To be able to do this in a structural way, the wavefunctions, $\psi_{i}$, are represented by a linear combinations of fixed functions $\varphi_{j}$.

$$
\psi_{i}=\sum_{j=0}^{N_{\varphi}} c_{j i} \varphi_{j}
$$

These basis functions are not allowed to vary through the SCF cycle, instead the coefficents $c_{j i}$ are optimized during the iteration. The problem has now been transposed from finding a set of functions to finding a set of numbers, i.e. the coefficients $c_{j i}$. The best description of electronic structure is given by the Slater-type orbitals (STO) ${ }^{61}$ which are similar to the radial atomic orbitals obtained from solving the Schrödinger equation for the hydrogen atom. These orbitals has an exponential factor of $e^{-\varsigma r}$, and is in general expressed as

$$
\varphi_{n}^{S T O}(\boldsymbol{r})=N \boldsymbol{r}^{n-1} e^{-\varsigma r}
$$

where $N$ is the normalisation factor, $n$ is a natural number corresponding to the principal quantum number $(n=1,2,3 \ldots)$, and $\varsigma$ is a constant related to the effective charge of the nuclei. The drawback with the STO is that the integrals involving them are computationally demanding. A more effective set of function is the Gaussian-type orbitals (GTO) ${ }^{62-64}$ which have the Gaussian form $e^{-\alpha r^{2}}$. It turns out to be convenient to use the Cartesian Gaussians, which have the form

$$
\varphi_{\operatorname{lmn}}^{G T O}(x, y, z)=N x^{l} y^{m} z^{n} e^{-\alpha\left(x^{2}+y^{2}+z^{2}\right)}
$$


where $l, m, n$ are related to quantum numbers and determines the type of orbitals, i.e. the $e^{-\alpha r^{2}}$ is a s-orbital, $x e^{-\alpha r^{2}}, y e^{-\alpha r^{2}}$ and $z e^{-\alpha r^{2}}$ are $\mathrm{p}$ orbitals etc. The drawback with GTO is that they drop off to quickly with $\boldsymbol{r}$ (since $\boldsymbol{r}^{2}$ instead of $\boldsymbol{r}$ in the exponent). They also have an incorrect behaviour around $\boldsymbol{r}=0$ which can have serious effects for properties depending on electron density at the nuclei, e.g. electron spin resonance coupling constants. Hence more Gaussians have to be used compared to STOs. Normally the basis set is constructed by approximating the STOs with a combination of GTOs, e.g. the STO-3G basis set ${ }^{65,66}$ is a STO approximated by 3 GTOs. A basis set constructed from a set of GTOs is referred to as a contracted basis function and the individual GTOs are called primitive Gaussians.

The smallest possible all-electron basis set is referred to as a single zeta basis set or a minimal basis set and has only one basis function for each atomic orbital, e.g. STO-3G. In a double zeta basis set there is two basis functions for each atomic orbital, for a triple zeta basis set there is three basis functions for each atomic orbital etc. Examples of such basis sets are the correlation-consistent polarized Core and Valence (Double/Triple/etc.) Zeta basis set by Dunning et al. (cc-pCVDZ, cc-pCVTZ, etc.) ${ }^{67,68}$.

Since the interaction between atoms mainly affects the valence electrons, the basis set can be split into two parts, one simpler part for the core orbitals and one more precise part for the valence orbitals. This is called a splitvalence basis set or a valence-multiple-zeta basis set. The core orbitals are typically represented by one basis function per orbital while the valence orbitals is represented by two or more basis function per orbital. Examples of split-valence basis sets are the basis sets by Pople et al. $3-21 \mathrm{G}^{69}, 6-21 \mathrm{G}$ ${ }^{69}, 6-31 \mathrm{G}^{70,71}$ and $6-311 \mathrm{G}^{72}$ where the first number indicates the number of primitive Gaussians used in the contracted core functions. The number of digits after the hyphen indicates what type of zeta that is used in the valence function, e.g. two digits means double zeta basis set etc. The digits themselves indicates the number of primitives in the respective valence function. For example, 3-21G has three primitives in the core functions, the valence orbitals is represented with a double zeta basis set where the first 
function has two primitive Gaussians and the second function has one primitive Gaussian.

For large atoms the distinction between core and valence electrons can be developed even further by replacing the inner core electrons and nuclei with an effective core potential (ECP), also referred to as pseudopotential. This is more or less necessary to do for very large atoms since the basis set otherwise would be practically intractable. Basis sets that uses pseudopotentials are for example LANLDZ ${ }^{73,74}$ and SDD ${ }^{75}$.

Further improvement is the inclusion of polarization and/or diffuse functions. Inclusion of polarization is usually done by including basis functions corresponding to quantum numbers of higher angular momenta than the valence orbitals. The inclusion of polarization functions is typically noted with a star “*”, e.g. 6-31G*, but can also be noted in a more descriptive way, e.g. 6-31G(2d,p) which means two additional set of $d$-functions for heavy atoms and one additional $p$-function for the first row elements. Diffuse functions is typically included to allow weakly bonded electrons to localize far from the remaining density. This is facilitated by including additional sets of $s$ and $p$ functions with small exponents which makes the functions more smeared out. The use of diffuse functions is indicated by a plus "+" for the Pople's basis sets, e.g. 6-31+G, and by the prefix "aug" for the Dunning's basis sets, e.g. aug-cc-pCVDZ.

The choice of basis set is crucial to obtain computational results in agreement with experiments. A suitable sophisticated basis set must be used to obtain accurate results, but there will always be a trade-off between accuracy and computational cost.

\subsection{Thermochemistry}

\subsubsection{The Partition Function}

The theory of quantum mechanics implies that the energy states for a system of particles, e.g. atoms and molecules, are quantized when subject to suitable boundary conditions ${ }^{76}$. The energy states with corresponding energy are obtained by solving the Schrödinger equation. The distribution of atoms or molecules over these energy states is described by the Boltzmann 
distribution ${ }^{77,78}$. The Boltzmann distribution states that the probability $p_{i}$ for the system to be in the state with energy $E_{i}$ is

$$
p_{i} \propto e^{-\frac{E_{i}}{k_{B} T}}
$$

where $k_{B}$ is the Boltzmann constant and $T$ is the temperature. Since the sum of the probabilities $p_{i}$ needs to be 1 , i.e. the probability to find the system in any state is equal to 1 , a normalization factor is needed. This factor is expressed as $1 / Q$ where

$$
Q=\sum_{i} e^{-\frac{E_{i}}{k_{B} T}}
$$

Each state of a set of degenerate states is considered as an individual state in the formula above. The quantity $Q$ is called a partition function and many properties for a system is possible to derive from this function. The energies $E_{i}$ will depend on the number of particles, $N$, and the volume, $V$, of the system and will therefore be denoted $E_{i}(N, V)$. The probability factors $p_{i}$ also depends on the temperature $T$ and hence the partition function $Q$ will depend on $N, V$ and $T$ and will be denoted $Q(N, V, T)$. Sometimes, for convenience, $T$ is replaced by $\beta=1 / k_{B} T$ giving $Q(N, V, \beta)$ instead. For a system with distinguishable independent particles the total energy $E_{i}(N, V)$ for state $i$ can be expressed as a sum of the energies for each individual particle

$$
E_{i}(N, V)=\varepsilon_{a}^{1}(V)+\varepsilon_{b}^{2}(V)+\varepsilon_{c}^{3}(V)+\cdots
$$

where $\varepsilon_{a}^{1}$ denotes the energy for particle 1 in state $a$. The $N$ dependency simply comes from the number of terms in equation (25). This results in

$$
Q(N, V, T)=\sum_{i} e^{-\frac{E_{i}}{k_{B} T}}=\sum_{a, b, c, \ldots} e^{-\frac{\varepsilon_{a}^{1}(V)+\varepsilon_{b}^{2}(V)+\varepsilon_{c}^{3}(V)+\cdots}{k_{B} T}}
$$

and since the particles are distinguishable can be written

$$
Q(N, V, T)=q_{1}(V, T) q_{2}(V, T) q_{3}(V, T) \ldots
$$

where each $q_{i}(V, T)$ is given by

$$
q_{i}(V, T)=\sum_{a} e^{-\frac{\varepsilon_{a}^{i}(V)}{k_{B} T}}
$$

The particles of a system is typically a set of molecules hence the $q_{i}(V, T)$ is called a molecular partition function. In most cases the particles is not distinguishable and equation (27) is not valid and we need to consider 
fundamental properties of all particles. For example with a system of fermions, e.g. electrons, the Pauli exclusion principle states that two particles cannot occupy the same quantum state ${ }^{41}$. The indices $a, b, c, \ldots$ in equation (26) is therefore not independent and cannot be written as a product of individual summations as done in equation (27). By making the assumption that the number of states with energies less then $\sim k_{B} T$ is much larger than the number of particles a good approximation can be derived.

$$
Q(N, V, T)=\frac{[q(V, T)]^{N}}{N !}
$$

The molecular partition function, $q(V, T)$, can be further separated into a translational part $q_{\text {trans }}(V, T)$, a vibrational part $q_{v i b}(T)$, a rotational part $q_{\text {rot }}(T)$ and an electronic part $q_{\text {elec }}(T)$.

$$
q(V, T)=q_{\text {trans }}(V, T) q_{v i b}(T) q_{\text {rot }}(T) q_{\text {elec }}(T)
$$

If approximating the molecules as atoms in a monoatomic ideal gas the transitional partition function becomes

$$
q_{\text {trans }}(V, T)=\left(\frac{2 \pi m k_{B} T}{h^{2}}\right)^{3 / 2} V
$$

The vibrational motion of a polyatomic molecule can be approximated as a set of independent harmonic oscillators where each oscillator corresponds to a normal mode $i$ with the energy

$$
\varepsilon_{i}=\left(\mathrm{v}_{i}+\frac{1}{2}\right) h\left(\frac{k_{i}}{\mu_{i}}\right)^{1 / 2} \frac{1}{2 \pi}=\left(\mathrm{v}_{i}+\frac{1}{2}\right) h v_{i}
$$

where $\mathrm{v}_{i}=0,1,2, \ldots$ is the vibrational quantum number, $k_{i}$ is the force constant, $\mu_{i}$ is the reduced mass and $v_{i}$ is the vibrational frequency for normal mode $i$. The total vibrational energy for a molecule with a vibrational degree of freedom of $\alpha$ is

$$
\varepsilon_{v i b}=\sum_{i=1}^{\alpha}\left(\mathrm{v}_{i}+\frac{1}{2}\right) h v_{i}
$$

The vibrational degree of freedom depends on the number of atoms $n$ in the molecule, $3 n-5$ for a linear molecule and $3 n-6$ for a nonlinear molecule. The vibrational partition function for such a molecule becomes

$$
q_{v i b}(T)=\prod_{i=1}^{\alpha} \frac{e^{-\Theta_{v i b, i / 2 T}}}{\left(1-e^{-\Theta_{v i b, i / T}}\right)}
$$


where $\Theta_{v i b, i}$ is the vibrational temperature for normal mode $i$ and $\Theta_{v i b, i}=$ $h v_{i} / k_{B}$.

The rotational partition function for a one dimensional linear molecule can be obtained using the rigid rotator model with the energy levels

$$
\varepsilon_{J}=\frac{\hbar^{2} J(J+1)}{2 I}
$$

where $J=0,1,2, \ldots$ is the angular quantum number and $I$ is the moment of inertia of the rotator. For each angular quantum number there is a corresponding set of magnetic quantum numbers $m_{J}=-J,-(J-$ $1), \ldots, 0, \ldots J-1, J$. Thus each rotational energy level has a degeneracy of

$$
g_{J}=2 J+1
$$

The rotational partition function can be written as a sum of energy levels instead of states.

$$
q_{\text {rot }}(\beta)=\sum_{J=0}^{\infty} g_{J} e^{-\beta \varepsilon_{J}}
$$

By approximating the summation with an integral and evaluating it, the rotational partition function for a linear molecule becomes

$$
q_{\text {rot }}(T)=\frac{8 \pi^{2} I k_{B} T}{h^{2}}=\frac{T}{\Theta_{\text {rot }}}
$$

This approximation is valid at ordinary temperatures where the rotational temperature, $\Theta_{\text {rot }}$, is much smaller than $T$. Due to symmetry reasons equation (38) needs to include a symmetry number $\sigma$, where $\sigma=1$ is for unsymmetrical linear molecules and $\sigma=2$ is for symmetrical linear molecules.

$$
q_{\text {rot }}(T)=\frac{T}{\sigma \Theta_{\text {rot }}}
$$

For the general case with polyatomic molecules spreading in all three dimensions the rotational partition function is described as a combination of three one-dimensional rotational partition functions.

$$
q_{r o t}(T)=\frac{\pi^{1 / 2}}{\sigma}\left(\frac{T^{3}}{\Theta_{r o t, x} \Theta_{r o t}, y \Theta_{r o t}, z}\right)^{1 / 2}
$$

The symmetry number $\sigma$ depends on the symmetry of the polyatomic molecule, e.g. $\mathrm{NH}_{3}$ has a three-fold symmetry and therefore $\sigma=3$. 
The electronic partition function is obtained by using energy levels with degeneracy $g_{e}$ instead of energy states and can be expressed similar to equation (37) in the rotational case.

$$
q_{\text {elec }}(\beta)=\sum_{i} g_{e, i} e^{-\beta \varepsilon_{e, i}}
$$

where $\varepsilon_{e, i}$ is the energy for the electronic level $i$. This function can be greatly simplified by assuming that the excitation energy from the ground level to the first excited level is much larger than $k_{B} T$. Thus all excited levels are inaccessible and only the ground electron level needs to be included. Further, by defining the ground level electronic energy as zero, the electron partition function becomes

$$
q_{\text {elec }}(T)=g_{e, 0}
$$

which simply is the spin multiplicity of the molecule in the ground state ${ }^{76}$.

\subsubsection{Thermochemical Quantities}

Once the partition function for a system of particles is obtained a number of properties for the system can be calculated ${ }^{76}$. A distribution of particles over a set of energy states in a system with constant volume and with a fixed number of particles has an average energy $\langle E\rangle$. The average energy $\langle E\rangle$, also referred to as internal thermal energy or observed energy, $U$, can be obtained from the partition function according to

$$
U=\langle E\rangle=k_{B} T^{2}\left(\frac{\partial \ln Q}{\partial T}\right)_{N, V}
$$

By using the approximation in equation (29) the average energy can be expressed by the molecular partition function $q$

$$
U=\langle E\rangle=N k_{B} T^{2}\left(\frac{\partial \ln q}{\partial T}\right)_{V}
$$

From the internal thermal energy $U$, the constant-volume heat capacity is defined as

$$
C_{V}=\left(\frac{\partial U}{\partial T}\right)_{N, V}
$$

Since the pressure rather than volume is constant for most chemical processes the enthalpy is a more practical quantity to use. The relation between internal thermal energy $U$ and the enthalpy $H$ is

$$
H=U+p V
$$


where $p$ is the pressure and $V$ is the volume. The corresponding constantpressure heat capacity can be obtained from the enthalpy according to

$$
C_{p}=\left(\frac{\partial H}{\partial T}\right)_{N, p}
$$

It is not enough to consider the energy to predict in which direction a chemical process will spontaneously take, the change in entropy is also of importance. Entropy is related to the number of microscopic configurations for a certain macroscopic entity in a system, e.g. the number of energy state configurations giving the same total energy. Similar to the energy, the entropy, $S$, can also be calculated from the partition function.

$$
S=k_{B} T\left(\frac{\partial \ln Q}{\partial T}\right)_{N, V}+k_{B} \ln Q
$$

By using the approximation in equation (29) again, together with the Stirling approximation, $\ln N !=N \ln N-N$, the entropy can be expressed in terms of the molecular partition function.

$$
S=N k_{B}+N k_{B} \ln \frac{q}{N}+N k_{B} T\left(\frac{\partial \ln q}{\partial T}\right)_{V}
$$

Using the acquired entities energy and entropy additional important quantities such as Helmholtz and Gibbs free energies can now be calculated. The Helmholtz free energy, $A$, for a system will decrease for any spontaneous process that occur at constant temperature, volume and number of particles.

$$
A=U-T S
$$

The Gibbs free energy, $G$, is the equivalent of the Helmholtz free energy but with constant pressure instead of constant volume.

$$
G=H-T S
$$

The Gibbs free energy is more commonly used since chemical reactions usually occur at constant pressure.

\subsubsection{Thermochemical Equilibrium}

One of the most central relations in thermochemistry is the relation between the equilibrium constant, $K$, and the reaction Gibbs free energy, $\Delta_{r} G^{\ominus}$, at standard conditions.

$$
R T \ln K=-\Delta_{r} G^{\ominus}
$$


where $R$ is the gas constant. A general reaction can be expressed as

$$
0=\sum_{X} \eta_{X} X
$$

where $X$ denotes the substances and $\eta_{X}$ is the corresponding stoichiometric number, e.g. reaction $A+2 B \rightarrow 3 C$ has $\eta_{A}=-1, \eta_{B}=-2$ and $\eta_{C}=+3$. Each substance has an activity, $a_{X}$, which usually is replaced by concentration or partial pressure depending on situation. The equilibrium constant is then defined as

$$
K=\left(\prod_{X} a_{X} \eta_{X}\right)_{\text {equilibrium }}
$$

where the activities, $a_{X}$, have their equilibrium values, e.g. reaction $A+$ $2 B \rightarrow 3 C$ has $K=a_{A}{ }^{-1} a_{B}{ }^{-2} a_{C}{ }^{3}$. The reaction Gibbs free energy is calculated from

$$
\Delta_{r} G^{\ominus}=\sum_{X} \eta_{X} G_{X}^{\ominus}
$$

where $G_{X}^{\ominus}$ is the Gibbs free energy for substance $X$ at standard conditions. The equations (52), (54) and (55) can be used to calculate the activities (e.g. concentrations or partial pressures) for the substances at equilibrium by calculating $G_{X}^{\ominus}$ for each substance via the partition function. This can be expanded to include multiple reactions by first calculating the Gibbs free energy for each possible molecule in the set of reactants, products and byproducts, then minimizing the total Gibbs free energy for the set of molecules. The total Gibbs free energy can be expressed as a sum of chemical potentials

$$
G_{t o t}=\sum_{X} n_{X} \mu_{X}
$$

where $n_{X}$ is the number of moles and the chemical potential $\mu_{X}$ is defined as the partial molar Gibbs free energy.

$$
\mu_{X}=\left(\frac{\partial G_{t o t}}{\partial n_{X}}\right)_{p, T, n^{\prime}}
$$

where $n^{\prime}$ indicates the number of moles for all substances excluding substance $X$. For example, for an ideal gas

$$
\mu_{X}=\mu_{X}^{\ominus}+R T \ln \frac{p_{X}}{p^{\ominus}}
$$

where $\mu_{X}^{\ominus}=G_{X}^{\ominus}$. The task to find the equilibrium composition now transposes into minimizing a sum of chemical potentials which by themselves depends on the current composition and it is therefore solved 
through iteration. This can be done for different external pressures and temperatures and can therefore be used to find the optimal pressure and temperature to produce a certain product ${ }^{44}$.

\subsubsection{Thermochemical Kinetics}

Aside from the equilibrium distribution for a chemical system, the reaction rates is often of interest. The reaction rates, $\vec{v}$, tell how fast a reaction occurs and typically depends on the activities of the substances, e.g. proportional to the concentrations of reactants $A$ and $B$, giving

$$
\vec{v}=k[A][B]
$$

where $k$ is the reaction rate constant and $[X]$ is the concentration of substance $X$.

A chemical reaction is in general reversible i.e. can react in both the forward and reverse direction with different reaction rates. If the forward reaction rate is much larger than the reverse reaction rate the reaction is called irreversible. To be able to predict how a chemical system will behave it is essential to know the reaction rates. Most chemical reactions of interest has a transition state, which corresponds to the state of the molecular structure (or "activated complex") found at the saddle point on the potential energy profile between reactants and products (Figure 7). 


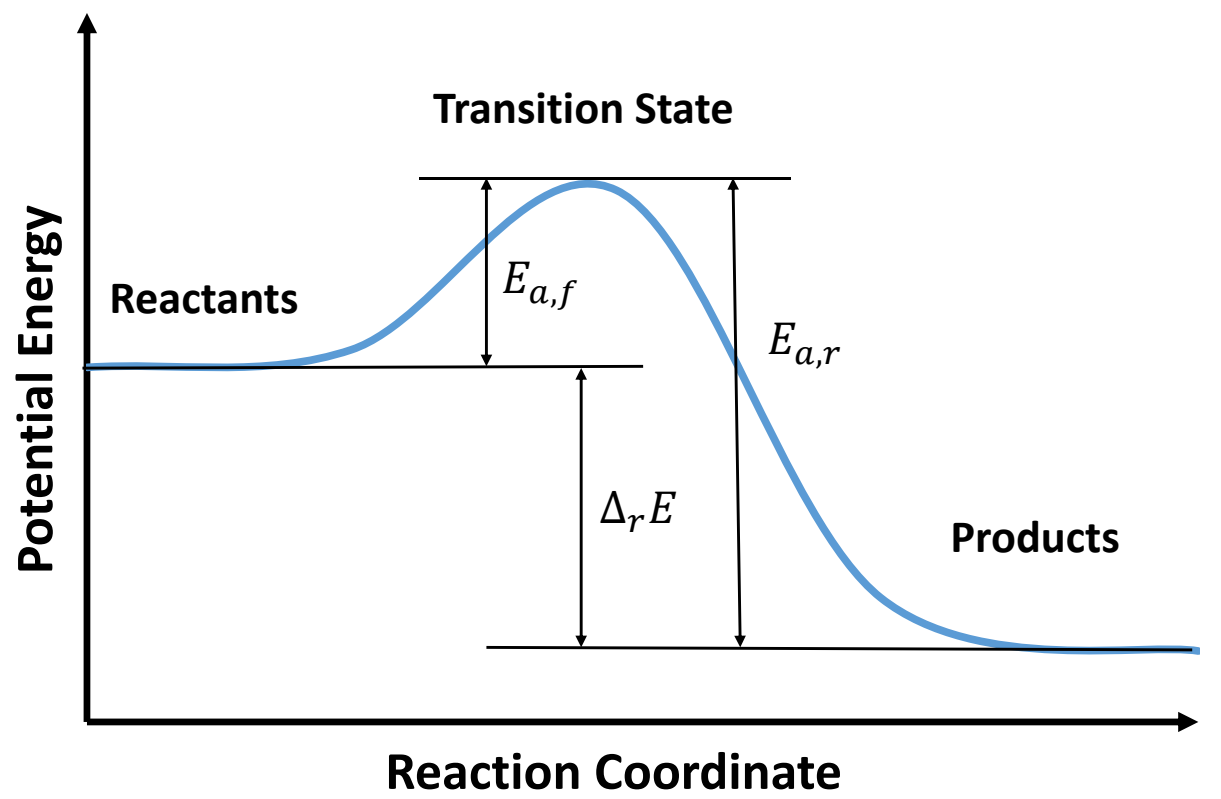

Figure 7. Schematic potential energy profile for a reaction. $E_{a, f}$ is the activation energy in the forward direction, $E_{a, r}$ is the activation energy in the reverse direction and $\Delta_{r} E$ is the reaction energy.

There will be an activation energy for both the forward reaction and for the reverse reaction. Since the reaction in Figure $\mathbf{7}$ is exothermic, the forward activation energy is smaller than the reverse activation energy. To calculate the reaction rate constants from the activation energy the transition state theory (TST), also referred to as activated complex theory (ACT), is applied. In TST a reaction between $A$ and $B$ is pictured as proceeding through the formation of an activated complex $C^{\ddagger}$, that decays into the product $P$ with a rate constant of $k^{\ddagger}$

$$
A+B \rightleftharpoons C^{\ddagger} \rightarrow P
$$

The decay of the active complex is proportional to the vibrational frequency, $v^{\ddagger}$, along the reaction coordinate giving

$$
k^{\ddagger}=\kappa v^{\ddagger}
$$

where $\kappa$ is the transmission constant, typically assumed to be about 1 . The concentration of $C^{\ddagger}$ is proportional to the concentrations of $A$ and $B$ with proportional constant $K^{\ddagger}$ which can be expressed using the partial pressure equilibrium constant $K$ giving the forward reaction rate 


$$
k_{f}=k^{\ddagger} K^{\ddagger}=\kappa v^{\ddagger} K^{\ddagger}=\kappa v^{\ddagger} K \frac{R T}{p^{\ominus}}
$$

where $p^{\ominus}$ is the standard pressure. It can be shown that the equilibrium constant $K$ can be calculated through the standard molar partition functions, $q_{m, X}^{\ominus}$, and the differences in ground state energy $E_{0}(X)$ for the reactants and products ${ }^{44}$, giving

$$
K=\frac{N_{A} q_{m, C^{\ddagger}}^{\ominus}}{q_{m, A}^{\ominus} q_{m, B}^{\ominus}} e^{-\left(E_{0}\left(C^{\ddagger}\right)-E_{0}(A)-E_{0}(B)\right) / R T}
$$

where $N_{A}$ is the Avogadro constant. Furthermore the standard molar partition function for the active complex can be separated into one part containing the vibrational frequency along the reaction coordinates, and one part containing the rest of the vibrational frequencies. By assuming $h v^{\ddagger} \ll k_{B} T$, the part corresponding to the reaction frequency simplifies to

$$
q^{\ddagger}=\frac{1}{1-e^{-h v^{\ddagger} / k_{B} T}}=\frac{1}{1-\left(1-\frac{h v^{\ddagger}}{k_{B} T}+\cdots\right)} \approx \frac{k_{B} T}{h v^{\ddagger}}
$$

Hence, the standard molar partition function for the active complex can be written as

$$
q_{m, C^{\ddagger}}^{\ominus}=\frac{k_{B} T}{h v^{\ddagger}} \bar{q}_{m, C^{\ddagger}}^{\ominus}
$$

where the bar over $q$ denotes the partition function for all modes except the vibrational mode along the reaction coordinate. By combining equation (60) - (63) the forward rate constant can be expressed as

$$
k_{f}=\kappa \frac{k_{B} T}{h} \frac{R T}{p^{\ominus}} \frac{N_{A} \bar{q}_{m, C^{\ddagger}}^{\ominus}}{q_{m, A}^{\ominus} q_{m, B}^{\ominus}} e^{-\left(E_{0}\left(C^{\ddagger}\right)-E_{0}(A)-E_{0}(B)\right) / R T}
$$

Or, by using Gibbs free energy of activation, $\Delta^{\ddagger} G$, i.e. difference in Gibbs free energy between reactants and the active complex, written as

$$
k_{f}=\kappa \frac{k_{B} T}{h} \frac{R T}{p^{\ominus}} e^{-\Delta^{\ddagger} G / R T}
$$

The forward rate constant can be compared to the familiar Arrhenius equation

$$
k_{f}=A e^{-E_{a, f} / R T}
$$

where $k_{f}$ is the forward reaction rate constant, $A$ is the pre-exponential factor (sometimes interpreted as the collision frequency) and $E_{a, f}$ is the forward activation energy. Thus by calculating the Gibbs free energies for the 
reactants, transition state structure and products, the forward and reverse activation Gibbs free energies are obtained. The reaction rates are then given by equation (67), and the kinetics for the reactions can be modelled by integrating the rate equations ${ }^{44}$.

\subsection{Computational Model}

Even though the computational resources available for simulations have been growing rapidly over the last decades, it is not possible to model all atoms in a macroscopic surface structure due to the computational cost. There are mainly two ways to create manageable models, either to cut out a minor portion of the system and treat it in a supermolecular approach, or to use a periodic model. In the periodic model approach, a unit cell is introduced which typically contains dozens of atoms. Periodic boundary conditions is then invoked to replicate the unit cell in either one, two or three dimensions usually corresponding to linear molecules, surfaces or bulk materials respectively, see Figure 8. This enables a large material model whilst quantum chemical calculations only are required for the small unit cell with additional schemes to handle the interactions with the periodically repeated images. 


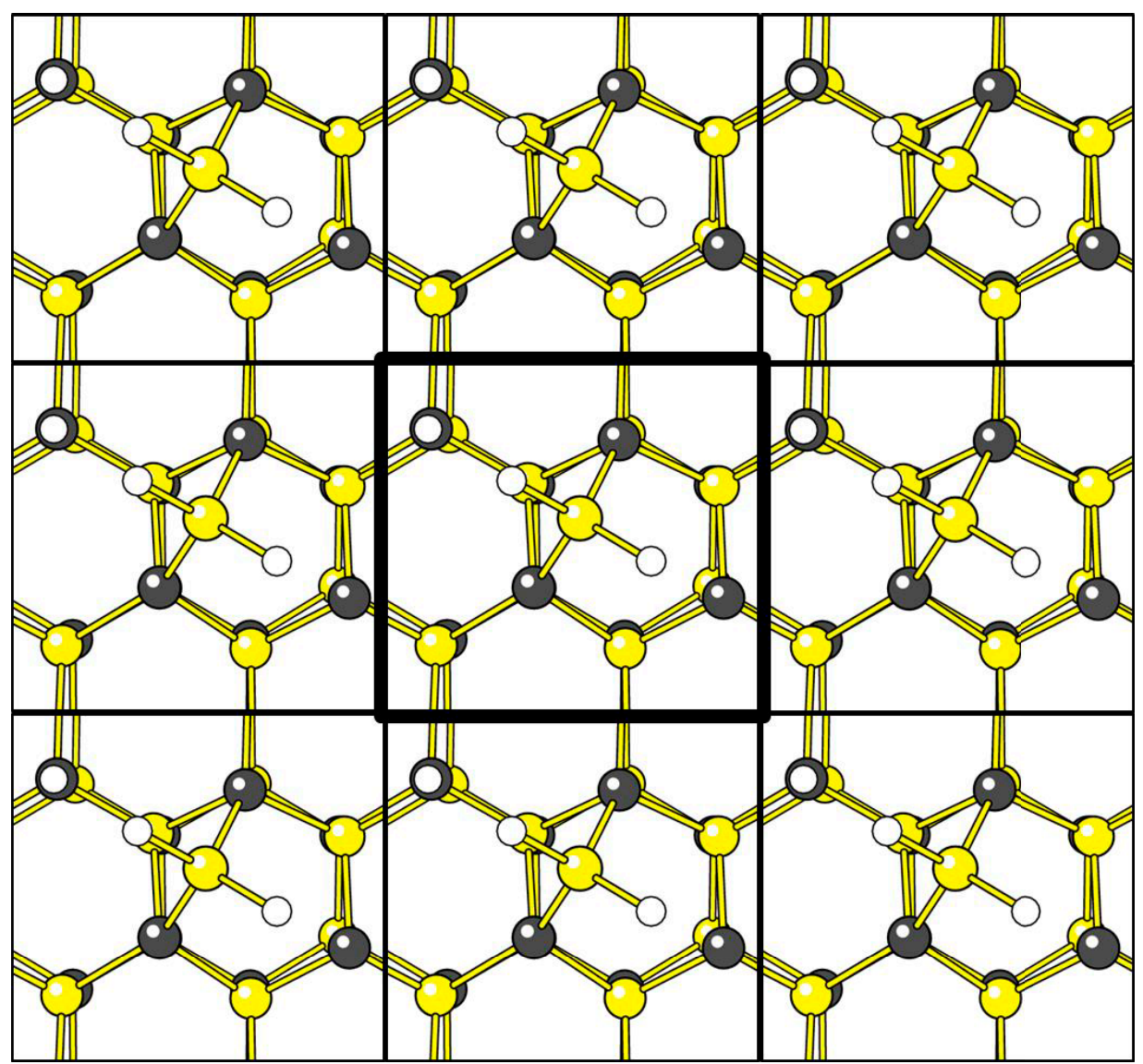

Figure 8. A periodic model of a silicon carbide surface with an adsorbed $\mathrm{SiH}_{2}$ molecule.

In the supermolecular approach instead of trying to make an approximated large model, as in the periodic case, the materials themselves are approximated using a small part of the system. Thus the surface and bulk structures are modelled as clusters, typically consisting of 10-100 or more atoms, see Figure 9. In this thesis, where the processes studied mainly are either gas phase or gas phase - solid interface reactions, the cluster model is a natural model to use in the quantum chemical calculations when nanoparticle-like systems are studied. Albeit care must be taken to ensure that the properties computed have converged with respect to cluster size. The supermolecular approach can also be used to study reactions at actual extended surfaces, like in CVD, but also here it is necessary to use a 
sufficiently large cluster representing the surface to minimize boundary effects.

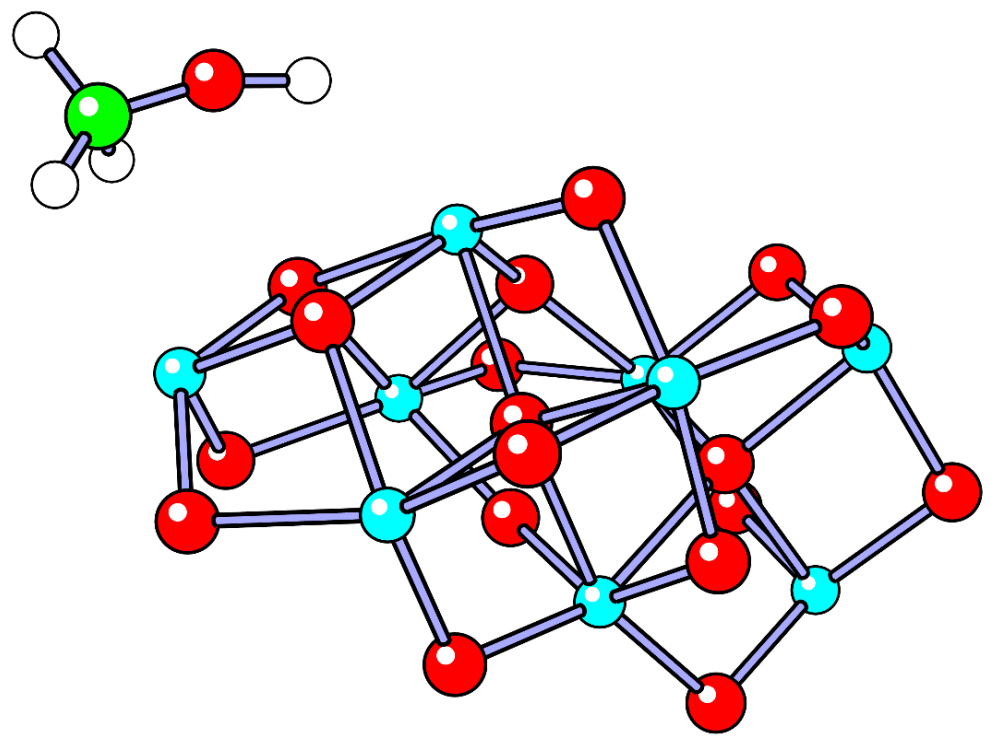

Figure 9. A supermolecular cluster model of a nanoparticle, or of a piece of the surface, of zirconium(IV) oxide with an interacting methanol molecule.

The clusters are obtained by cutting out appropriate sized parts from the crystal structures of the material which is modelled, e.g. $4 \mathrm{H}-\mathrm{SiC}^{79,80}$ and monoclinic $\mathrm{ZrO}_{2}{ }^{81}$. In this thesis work the quantum chemical calculations are carried out using the Gaussian09 ${ }^{82}$ software. The initial structures, taken from the crystal structures, is typically allowed to relax during a geometry optimization using the Berny algorithm ${ }^{83}$ to find the lowest energy geometries for the clusters. Then the reactant molecules is introduced and placed at a possible reaction site. The system is again geometry optimized and adsorption energies can be obtained. In fact, all thermochemical properties such as energy $U$, entropy $S$, heat capacity $C_{V}$, enthalpy $S$ and Gibbs free energy $G$ can be obtained from the partition function, for a given relaxed structure with knowledge of the geometries and the vibrational normal mode frequencies (within the harmonic approximation). The equilibrium distribution for the system can now also be calculated from the Gibbs free energies. 
Reaction coordinates and transition states can also be found, either by moving the reactant coordinates to the product coordinates on the potential energy surface, or more specifically using the synchronous transit-guided quasi-newton (STQN) method ${ }^{84,85}$ provided by the Gaussian09 program, which uses a quadratic synchronous transit (QST) approach ${ }^{86}$ followed by a quasi-Newton algorithm. With knowledge of the free energies for the reactants, the transition states and the products, the kinetic time evolution of the reaction can be determined. 


\section{Results}

\subsection{Silicon carbide CVD}

The first three articles focus on reactions during CVD of silicon carbide. In order to increase the growth rate whilst avoiding surface defects during epitaxial growth, chlorine is often introduced to the CVD process. In paper I, the effect of the addition of chlorine on the surface chemistry was studied by comparing the adsorption of the, thermochemically, most abundant I species $\mathrm{SiH}_{2}$ and $\mathrm{SiCl}_{2}$ on the $4 \mathrm{H}-\mathrm{SiC}(000 \overline{1})$ surface. It was shown that the $\mathrm{SiH}_{2}$ molecule adsorbed (i.e. chemisorbed) roughly $100 \mathrm{~kJ} / \mathrm{mol}$ more strongly than the $\mathrm{SiCl}_{2}$ molecule on the unsaturated surface. The activation energy for adsorption of $\mathrm{SiH}_{2}$ on a fully hydrogen-terminated surface (where a $\mathrm{SiH}_{3}$ unit with a $\mathrm{Si}-\mathrm{C}$ bond to the surface $\mathrm{C}$ was formed) was roughly 140 $\mathrm{kJ} / \mathrm{mol}$ lower than the corresponding activation energy for $\mathrm{SiCl}_{2}$. It should be noted that these activation energies also implies that once adsorbed, the $\mathrm{SiCl}_{2}$ molecule has a lower tendency to desorb than the $\mathrm{SiH}_{2}$ molecule. Another important observation was that the $\mathrm{SiCl}_{2}$ molecule physisorbed somewhat stronger than the $\mathrm{SiH}_{2}$ molecule on the hydrogen terminated surface. This might be an important factor for the initialization of the chemisorption reaction.

The activation energies for surface diffusion of chemisorbed $\mathrm{SiH}_{2}$ and $\mathrm{SiCl}_{2}$ on the fully hydrogen-terminated $\mathrm{SiC}$ surface was $291 \mathrm{~kJ} / \mathrm{mol}$ and 339 $\mathrm{kJ} / \mathrm{mol}$ respectively, which are high values making diffusion on a fully terminated surface difficult. On a SiC surface lacking hydrogen termination, these activation energies were significantly lower, $121 \mathrm{~kJ} / \mathrm{mol}$ for $\mathrm{SiH}_{2}$ and $107 \mathrm{~kJ} / \mathrm{mol}$ for $\mathrm{SiCl}_{2}$. Thus $\mathrm{SiH}_{2}$ will diffuse more easily compared to $\mathrm{SiCl}_{2}$ on a fully hydrogen terminated surface, while the $\mathrm{SiCl}_{2}$ molecule diffuses slightly more easily than the $\mathrm{SiH}_{2}$ molecule on a bare surface. Both molecules diffuse significantly easier on a bare or a partially hydrogen terminated surface than on a fully $\mathrm{H}$-saturated surface. 
In paper II the addition of bromine was studied and compared with the chlorinated chemistry. The experimental results showed that the growth rate is on average $10 \%$ higher for brominated chemistry compared to chlorinated chemistry while maintaining the same high material quality. Quantumchemical calculations were performed for bromine-containing $\mathrm{Si}$ species as well as for other possible molecular intermediates in the gas phase. The quantum-chemical energetic data were used together with data from the literature in thermochemical computations of the species' equilibrium distributions (by minimizing the total Gibbs free energy of the system with respect to the amounts of the different species under the condition that the total amounts of each type of atom be conserved). Thermochemical calculations of the gas species distribution at equilibrium were made at constant pressure (100 mbar) and temperatures ranging from 1200 to 1700 ${ }^{\circ} \mathrm{C}$ for a gas mixture composition of $\mathrm{Si} / \mathrm{H}_{2}=0.25 \%, \mathrm{C} / \mathrm{Si}=1.0$, and $\mathrm{Cl} / \mathrm{Si}=$ 4.0 or $\mathrm{Br} / \mathrm{Si}=4.0$, see Figure 10 .

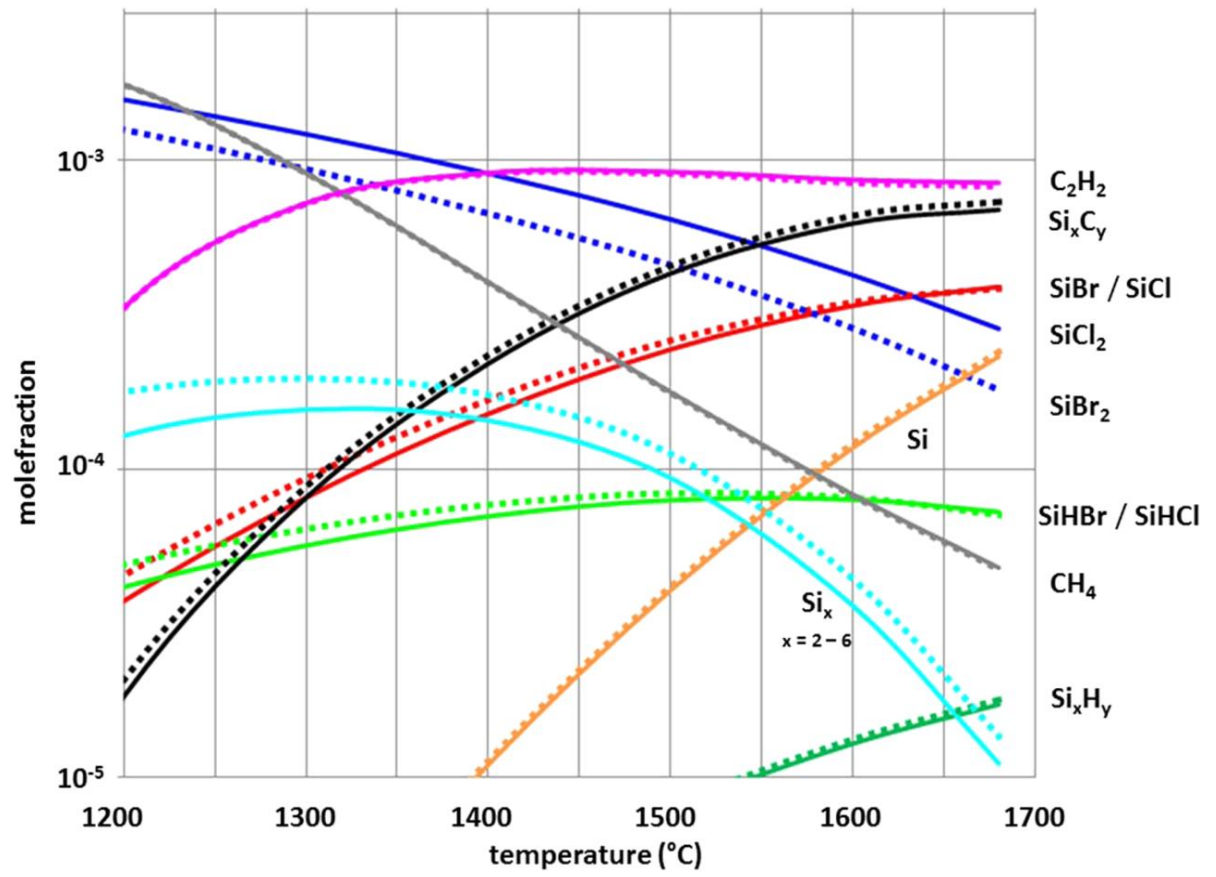

Figure 10. Mole fractions of the most abundant species at thermodynamic equilibrium vs temperature. Solid lines represent the $\mathrm{Si}-\mathrm{C}-\mathrm{Cl}-\mathrm{H}$ system, whereas dotted lines represent the $\mathrm{Si}-\mathrm{C}-\mathrm{Br}-\mathrm{H}$ system. Adopted from paper II. 
The equilibrium distributions (Figure 10) show that, at growth temperatures of $1500-1600{ }^{\circ} \mathrm{C}$, most of the silicon is in the form of small $\mathrm{Si}_{\mathrm{x}} \mathrm{C}_{\mathrm{y}}$ species (mainly $\mathrm{Si}_{2} \mathrm{C}$ ). The gas phase chemistry is similar between the chlorine and bromine containing species and $\mathrm{SiX}$ and $\mathrm{SiX}_{2}(\mathrm{X}=\mathrm{Cl}$ or $\mathrm{Br})$ have the highest concentration at normal growth temperatures. It is also noted that silicon clusters are formed at lower temperatures but decomposes at temperatures above $1400{ }^{\circ} \mathrm{C}$. Thermochemical calculations at different $(\mathrm{Cl}$ or $\mathrm{Br})$ to $\mathrm{Si}$ ratios show an increase of the $\mathrm{SiX}_{2}$ species $(\mathrm{X}=\mathrm{Cl}$ or $\mathrm{Br})$ at higher ratio $\mathrm{X} / \mathrm{Si}$ which suggest that $\mathrm{SiX}_{2}$ is active in $\mathrm{SiC}$ etching where higher concentrations of $\mathrm{Cl}$ or $\mathrm{Br}$ is used.

Bromine chemistry was further investigated by complementing the adsorption calculations from paper I with the adsorption reaction for $\mathrm{SiBr}_{2}$ on the $4 \mathrm{H}-\mathrm{SiC}(000 \overline{1})$ surface. The adsorption reaction for $\mathrm{SiBr}_{2}$ was found to have a similar energy curve as the $\mathrm{SiCl}_{2}$ molecule, se Figure 11.

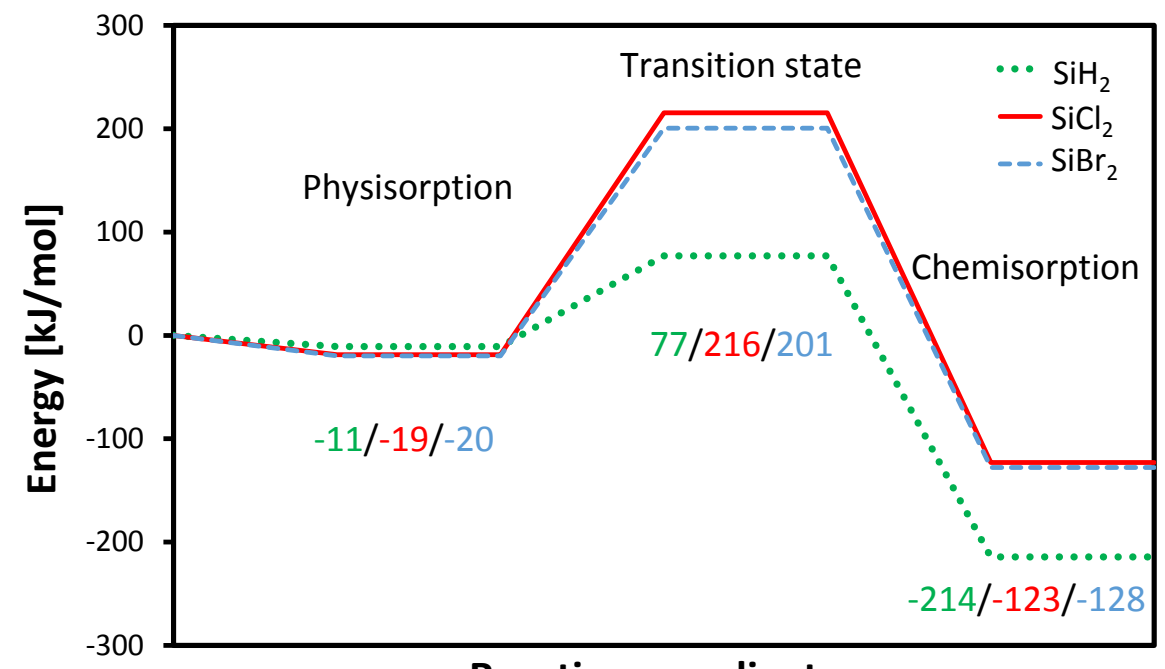

Reaction coordinates

Figure 11. Energy curve for the adsorption of $\mathrm{SiH}_{2}, \mathrm{SiCl}_{2}$ and $\mathrm{SiBr}_{2}$ adopted from paper II.

In paper III, adsorption studies of active $\mathrm{Si}$-species was extended with their

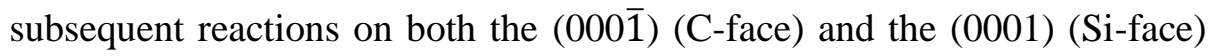
$4 \mathrm{H}-\mathrm{SiC}$ surface. Five $\mathrm{Si}$-species was considered, $\mathrm{SiH}, \mathrm{SiH}_{2}, \mathrm{SiCl}, \mathrm{SiHCl}$, and $\mathrm{SiCl}_{2}$. It has been shown previously ${ }^{87}$ that three surface adsorption modes 
( $\mathrm{CH}_{3}$ (ads), $\mathrm{CH}_{2}$ (ads), and $\mathrm{C}_{2} \mathrm{H}_{4}(\mathrm{ads})$ ) on the $\mathrm{Si}$-faced surface result from the adsorptions of gaseous hydrocarbons. These sites were used in modeling the adsorption on the (0001) surface, see Figure 12. On the $\mathrm{C}$ face, two adsorption sites, $\mathrm{H}(\mathrm{ads})$ (i.e. hydrogen terminated $\mathrm{C}$ site) and *(ads), (i.e. C site with a dangling bond) were considered, see Figure 12.

a)

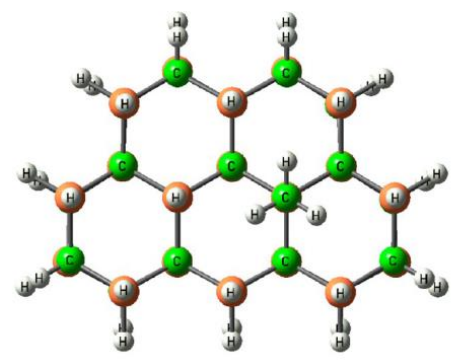

d)

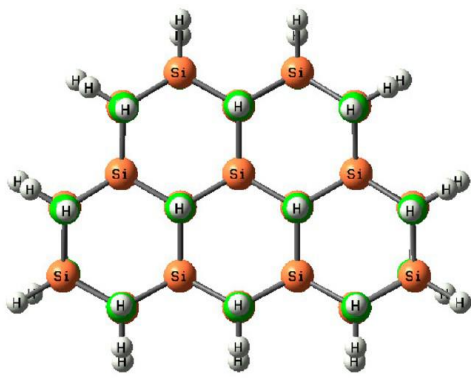

b)

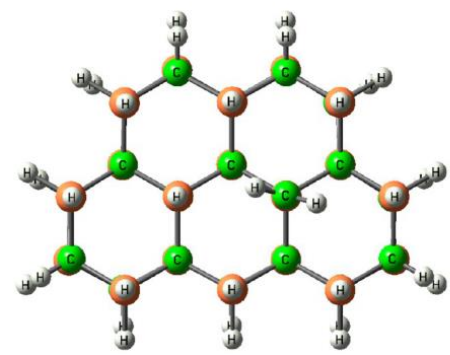

e)

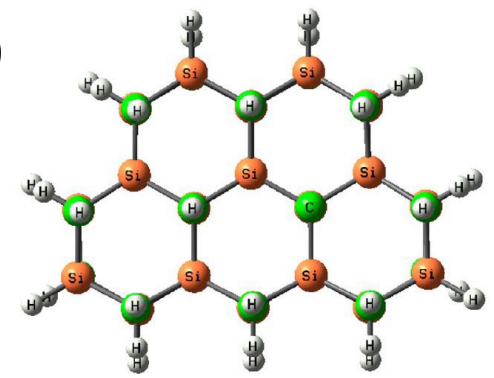

c)

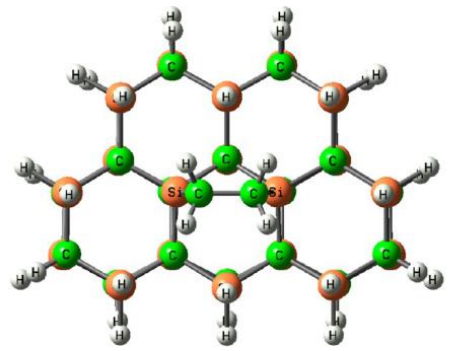

Figure 12. Top view of a) $\mathrm{CH}_{3}$ (ads), b) $\mathrm{CH}_{2}$ (ads), and c) $\mathrm{C}_{2} \mathrm{H}_{4}$ (ads) deposited on the $\mathrm{Si}$ face and d) $\mathrm{H}$ (ads) and e) *(ads) on the $\mathrm{C}$ face of the $\mathrm{Si}_{19} \mathrm{C}_{19}$ cluster. Adopted from paper III.

To obtain reliable results while keeping the computational cost at a reasonable level it is important to find a suitable functional and basis set. It is also important to investigate the size effects of the model. For example, one part of the basis set benchmarking used for calculations performed on a bromine system is shown in Table 2. The 6-311(d,p) basis set was concluded to be adequate for the majority of the calculations. 
Table 2. Basis set benchmarking for a bromine system using the reaction $\mathrm{SiH}_{4}+$ $\mathrm{Br}_{2} \rightarrow \mathrm{SiBr}_{2}+2 \mathrm{H}_{2}$

\begin{tabular}{|lr|}
\hline Functional/Basis set & Reaction energy [kJ/mol] \\
\hline B3LYP/6-31 & -149.1 \\
B3LYP/6-31G(d,p) & -116.8 \\
B3LYP/6-311G(d,p) & -83.2 \\
B3LYP/6-311(2d,2p) & -92.0 \\
B3LYP/6-311G(2df,2pd) & -88.2 \\
B3LYP/6-311++G(2df,2pd) & -89.6 \\
B3LYP/aug-cc-pVQZ & -85.3 \\
CCSD(T)/6-31G(d,p) & -133.5 \\
CCSD(T)/6-311++G(2df,2pd) & -89.4 \\
CCSD(T)/aug-cc-pVQZ & -96.0 \\
\hline
\end{tabular}

A similar approach was used to find a suitable cluster size. For example, reaction energies for adsorption of $\mathrm{SiH}_{2}$ and $\mathrm{SiCl}_{2}$ on different sized silicon carbide clusters was calculated and analyzed, see Table 3.

Table 3. Cluster size dependence, investigated through reaction $\operatorname{SiX}_{2}(g)+$ $\mathrm{H}($ ads $) \rightarrow \mathrm{SiX}_{2} \mathrm{H}$ (ads)

\begin{tabular}{|l|cr|}
\hline$\Delta_{\mathrm{R}} \mathrm{E}[\mathrm{kJ} / \mathrm{mol}]$ & $\mathrm{SiH}_{2}$ & $\mathrm{SiCl}_{2}$ \\
\hline $\mathrm{H}_{60} \mathrm{Si}_{33} \mathrm{C}_{33}$ & -214 & -123 \\
$\mathrm{H}_{72} \mathrm{Si}_{46} \mathrm{C}_{46}$ & -211 & -116 \\
$\mathrm{H}_{106} \mathrm{Si}_{81} \mathrm{C}_{81}$ & -210 & -114 \\
\hline
\end{tabular}

Calculations of properties for different sized cluster were also used to extrapolate to bulk values. For example, the silicon carbide band gap was obtained from calculating the energy difference between the lowest unoccupied molecular orbital and the highest occupied molecular orbital for increasing $\mathrm{SiC}$ cluster sizes (paper I).

The quantum chemical calculations of adsorption of $\mathrm{SiX}_{2}$ and $\mathrm{SiHX}$, $\left(\mathrm{X}=\mathrm{H}\right.$ and $\mathrm{Cl}$ ) on the (0001) surface showed that $\mathrm{SiH}, \mathrm{SiH}_{2}, \mathrm{SiCl}, \mathrm{SiHCl}$, and $\mathrm{SiCl}_{2}$ likely adsorb on a methylene site, which are shown to occur without the presence of transition states, see Table 4. 
Table 4. Energies $(0 \mathrm{~K})$, standard Gibbs free energies $\left(1600{ }^{\circ} \mathrm{C}\right)$ in $\mathrm{kJ} / \mathrm{mol}$, and sticking coefficients of $\mathrm{SiH}, \mathrm{SiH}_{2}, \mathrm{SiCl}, \mathrm{SiHCl}$, and $\mathrm{SiCl}_{2}$ on $\mathrm{CH}_{3}$ (ads), $\mathrm{CH}_{2}$ (ads), and $\mathrm{C}_{2} \mathrm{H}_{4}$ (ads) species predeposited on the $\mathrm{Si}$ face of $4 \mathrm{H}-\mathrm{SiC}$. The sticking coefficient is proportional to $\exp \left(-\Delta_{\mathrm{TS}} \mathrm{G}^{\circ} / \mathrm{RT}\right){ }^{88}$ and is further explained in paper III.

\begin{tabular}{|c|c|c|c|c|c|c|}
\hline Reaction\# & Molecule & $\Delta_{\mathrm{R}} \mathbf{E}^{\circ}$ & $\Delta_{\mathrm{TS}} \mathbf{E}^{\circ}$ & $\Delta_{\mathrm{R}} \mathrm{G}^{\circ}$ & $\Delta_{\mathrm{TS}} \mathrm{G}^{\circ}$ & $\mathbf{S}$ \\
\hline \multicolumn{7}{|c|}{ Adsorptions on $\mathrm{CH}_{3}(\mathrm{ads})$} \\
\hline $\mathrm{R} 1$ & $\mathrm{SiH}(\mathrm{g})$ & -157 & 82 & 94 & 325 & $3 \times 10^{-4}$ \\
\hline $\mathrm{R} 2$ & $\mathrm{SiH}_{2}(\mathrm{~g})$ & -203 & 88 & 91 & 364 & $3 \times 10^{-5}$ \\
\hline R3 & $\mathrm{SiCl}(\mathrm{g})$ & -124 & 106 & 146 & 358 & $4 \times 10^{-5}$ \\
\hline R4 & $\mathrm{SiHCl}(\mathrm{g})$ & -185 & 123 & 132 & 422 & $7 \times 10^{-7}$ \\
\hline R5 & $\mathrm{SiCl}_{2}(\mathrm{~g})$ & -134 & 190 & 177 & 492 & $8 \times 10^{-9}$ \\
\hline \multicolumn{7}{|c|}{ Adsorptions on $\mathrm{CH}_{2}(\mathrm{ads})$} \\
\hline R6 & $\mathrm{SiH}(\mathrm{g})$ & -320 & - & 15 & - & - \\
\hline R7 & $\mathrm{SiH}_{2}(\mathrm{~g})$ & -247 & - & 65 & - & - \\
\hline R8 & $\mathrm{SiCl}(\mathrm{g})$ & -306 & - & 37 & - & - \\
\hline R9 & $\mathrm{SiHCl}(\mathrm{g})$ & -226 & - & 113 & - & - \\
\hline R10 & $\mathrm{SiCl}_{2}(\mathrm{~g})$ & -183 & - & 128 & - & - \\
\hline \multicolumn{7}{|c|}{ Adsorptions on $\mathrm{C}_{2} \mathrm{H}_{4}(\mathrm{ads})$} \\
\hline R11 & $\mathrm{SiH}(\mathrm{g})$ & -275 & 140 & -11 & 379 & $9 \times 10^{-6}$ \\
\hline R12 & $\mathrm{SiH}_{2}(\mathrm{~g})$ & -327 & 206 & -28 & 460 & $5 \times 10^{-8}$ \\
\hline R13 & $\mathrm{SiCl}(\mathrm{g})$ & -245 & 148 & 36 & 388 & $7 \times 10^{-6}$ \\
\hline R14 & $\mathrm{SiHCl}(\mathrm{g})$ & -312 & 234 & 7 & 517 & $2 \times 10^{-9}$ \\
\hline R15 & $\mathrm{SiCl}_{2}(\mathrm{~g})$ & -273 & 275 & 50 & 522 & $2 \times 10^{-10}$ \\
\hline
\end{tabular}

The processes are thermodynamically less favorable than their reverse reactions and the sticking coefficients are seen to be small. However, additional calculations of subsequent surface reactions creating larger structures, showed that the structures have a stabilizing effect, see e.g. Figure 13. The formation of these larger structures is fast enough to compete with the desorption processes. 


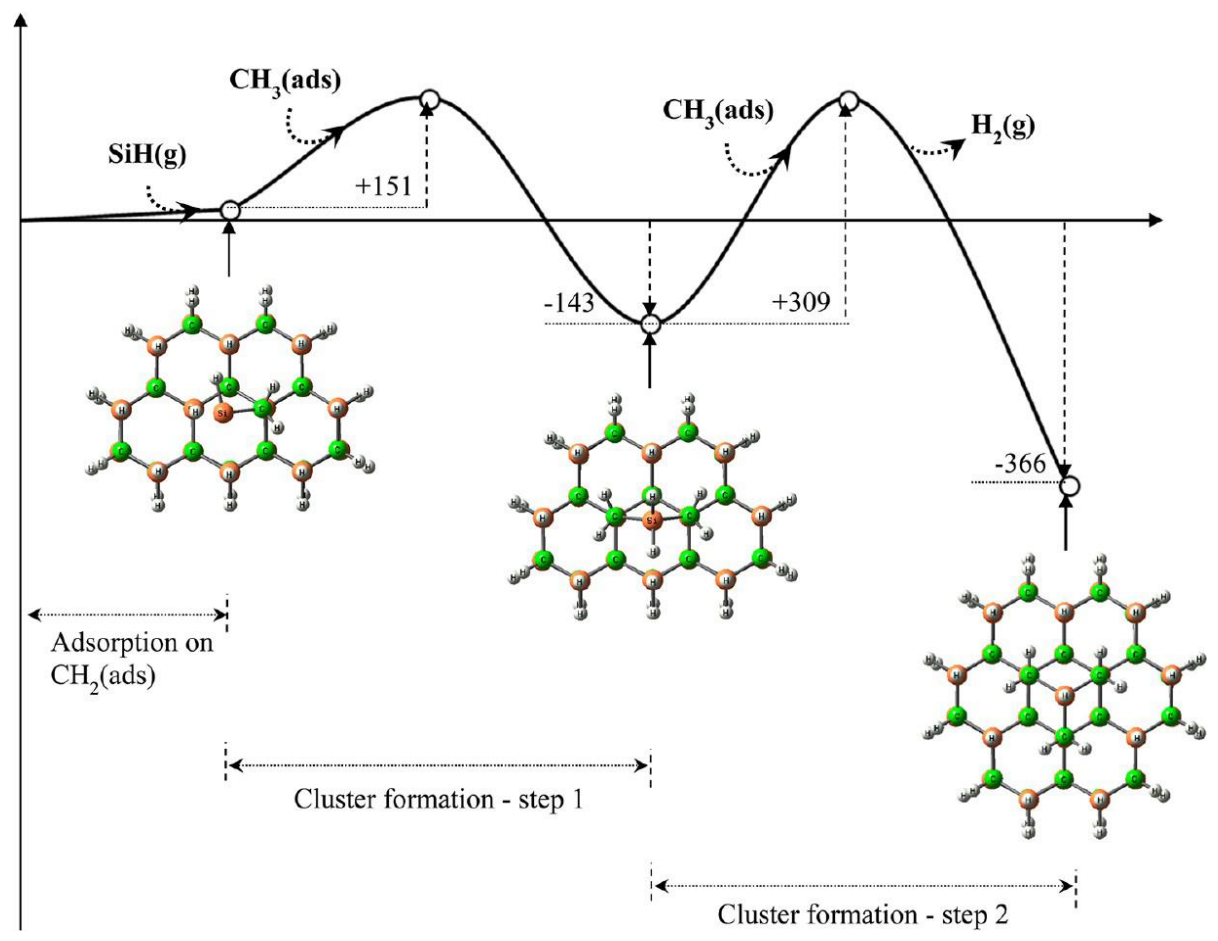

Figure 13. Reaction scheme of $\mathrm{SiC}$ growth from $\mathrm{SiH}(\mathrm{g})$ adsorption and formation of a larger adsorbed structure, adopted from paper III.

On the $(000 \overline{1})$ surface, the adsorptions likely occur on a surface site terminated by a dangling bond, *(ads), which are shown to occur without the presence of transition states and produce stable products, see Table 5. The $\Delta_{\mathrm{R}} \mathrm{G}^{\circ}$ from smallest to largest are $\mathrm{SiH}>\mathrm{SiCl}>\mathrm{SiH}_{2}>\mathrm{SiHCl}>\mathrm{SiCl}_{2}$ for both surfaces. 
Table 5. Energies at $0 \mathrm{~K}$ and standard Gibbs free energies at $1600{ }^{\circ} \mathrm{C}$ of the adsorption processes and sticking coefficients on $\mathrm{H}(\mathrm{ads})$ and $*(\mathrm{ads})$ on the $\mathrm{C}$ Face of $4 \mathrm{H}-\mathrm{SiC}$.

\begin{tabular}{|c|c|c|c|c|c|c|}
\hline Reaction\# & Molecule & $\Delta_{\mathrm{R}} \mathbf{E}^{\circ}$ & $\Delta_{\mathrm{TS}} \mathbf{E}^{\circ}$ & $\Delta_{\mathrm{R}} \mathbf{G}^{\circ}$ & $\Delta_{\mathrm{TS}} \mathbf{G}^{\circ}$ & $\mathbf{S}$ \\
\hline \multicolumn{7}{|c|}{ Adsorptions on $\mathrm{H}(\mathrm{ads})$} \\
\hline R16 & $\mathrm{SiH}(\mathrm{g})$ & -194 & 47 & 63 & 292 & $3 \times 10^{-3}$ \\
\hline $\mathrm{R} 17$ & $\mathrm{SiH}_{2}(\mathrm{~g})$ & -238 & 61 & 56 & 350 & $6 \times 10^{-5}$ \\
\hline R18 & $\mathrm{SiCl}(\mathrm{g})$ & -149 & 77 & 133 & 336 & $2 \times 10^{-4}$ \\
\hline R19 & $\mathrm{SiHCl}(\mathrm{g})$ & -207 & 116 & 123 & 422 & $8 \times 10^{-7}$ \\
\hline $\mathrm{R} 20$ & $\mathrm{SiCl}_{2}(\mathrm{~g})$ & -153 & 192 & 186 & 506 & $4 \times 10^{-9}$ \\
\hline \multicolumn{7}{|c|}{ Adsorptions on $*($ ads $)$} \\
\hline R21 & $\mathrm{SiH}(\mathrm{g})$ & -341 & - & -51 & - & - \\
\hline R22 & $\mathrm{SiH}_{2}(\mathrm{~g})$ & -301 & - & -1 & - & - \\
\hline R23 & $\operatorname{SiCl}(g)$ & -338 & - & -25 & - & - \\
\hline R24 & $\mathrm{SiHCl}(\mathrm{g})$ & -267 & - & 66 & - & - \\
\hline R25 & $\mathrm{SiCl}_{2}(\mathrm{~g})$ & -212 & - & 129 & - & - \\
\hline
\end{tabular}

Also, the Gibbs free energies for the adsorption of $\mathrm{Si}$ atoms, $\mathrm{SiX}, \mathrm{SiX}_{2}$, and $\mathrm{SiHX}$ where $\mathrm{X}$ is $\mathrm{F}$ or $\mathrm{Br}$ were investigated. Adsorption of $\mathrm{Si}$ atoms was shown to be the most thermodynamically favorable reaction followed by $\mathrm{SiX}, \mathrm{SiHX}$, and $\mathrm{SiX}_{2}, \mathrm{X}$ being a halide. The results in this study suggest that the major Si contributors in the $\mathrm{SiC}-\mathrm{CVD}$ process are $\mathrm{Si}$ atoms, $\mathrm{SiX}$ and $\mathrm{SiH}$.

\subsection{Methanol synthesis}

Methanol can be synthesized from gaseous carbon dioxide and hydrogen using solid metal-metal oxide mixtures acting as heterogeneous catalysts. Since a large surface area of the catalyst enhances the speed of the heterogeneous reaction, the use of nanoparticles (NP) is expected to be advantageous due to the NPs' large area to surface ratio. Hence, the plasmainduced creation of copper NPs was investigated in paper IV. One important factor during particle growth is the charging process where the variation of the work function (W) with particle size (Equation 69) is a key quantity, and the variation becomes increasingly pronounced at smaller NP sizes.

$$
W \approx W_{b u l k}-\frac{e^{2}}{8 \pi \varepsilon_{0} r_{N P}}
$$


The work function was computed for a set of NP charge numbers, sizes and shapes, using copper as a case study. The derived approximate analytical expression for $\mathrm{W}$ (Equation $\mathrm{X}$ ) was shown to give quite accurate estimates provided that the diameter of the NP is larger than about $0.5 \mathrm{~nm}$. The work function deviates from the approximate expression for diameters smaller than $0.5 \mathrm{~nm}$ depend on the charge number. In this size range where the work function depends on both the radius and the charge number, we demonstrate that the experimentally-based empirical expressions by Svanqvist and Hansen ${ }^{89}$ give reliable estimates of the work function.

An essential step in the methanol synthesis using a $\mathrm{Cu} / \mathrm{ZrO}_{2}$ nanoparticle catalyst is probably the conversion of $\mathrm{CO}_{2}$ to $\mathrm{CO}$ at the $\mathrm{ZrO}_{2}$ surface. This conversion is investigated in paper $\mathbf{V}$ by studying two different reaction paths, see Figure 14. The two paths result in the same complete reaction 2 $\mathrm{CO}_{2} \rightarrow 2 \mathrm{CO}+\mathrm{O}_{2}$ where $\mathrm{ZrO}_{2}$ (s) acts as a catalyst. 


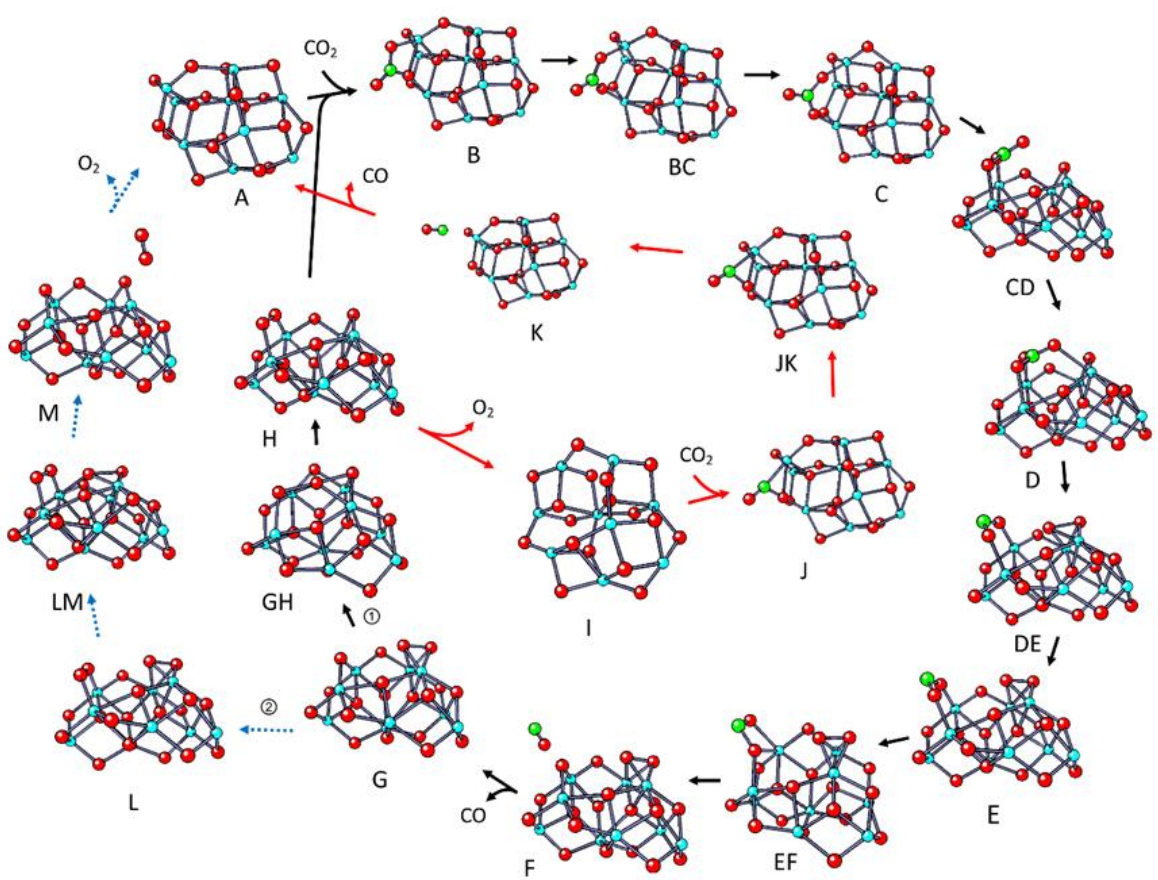

Figure 14. Scheme of $\mathrm{CO}_{2}$ conversion to $\mathrm{CO}$ and dioxygen reaction paths. Two different paths are shown, the first one is starting with A going to $\mathrm{H}$ and then following the red path back to A via I to $\mathrm{K}$. The second possibility is to go A to $\mathrm{H}$, then $\mathrm{B}$ to $\mathrm{G}$ followed by $\mathrm{L}$ and $\mathrm{M}$ back to $\mathrm{A}$ (blue dashed arrows). Adopted from paper $\mathrm{V}$.

The highest activation energy obtained for the catalytic reaction was 488 $\mathrm{kJ} / \mathrm{mol}$ which is roughly $100 \mathrm{~kJ} / \mathrm{mol}$ lower than that of the non-catalyzed gas phase reaction. The highest energy point compared to the initial energy is $651 \mathrm{~kJ} / \mathrm{mol}$ (structure I) for the path which involves a vacancy. This is approximately $120 \mathrm{~kJ} / \mathrm{mol}$ lower than for the gas phase reaction. In particular one should note the reaction path which involves an oxygen vacancy (red arrows from structure I to A). If the vacancy (structure I) can be formed by other less energy demanding processes, possibly with help of reaction by hydrogen gas or catalyzation by copper metal particles, this is a very promising path since the $\mathrm{CO}_{2}$ to $\mathrm{CO}$ conversion reaction is almost spontaneous with the final $\mathrm{CO}$ desorption step as highest energy barrier (52 $\mathrm{kJ} / \mathrm{mol}$ ), see Figure 15. 


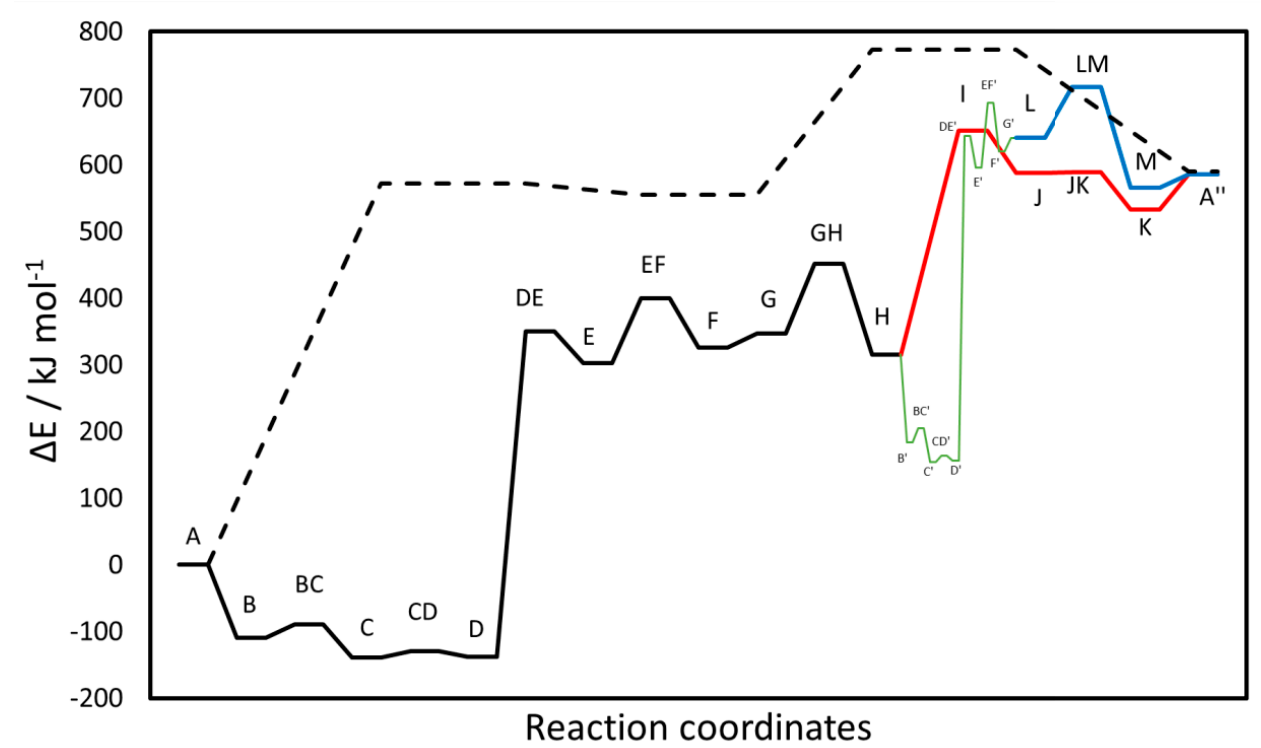

Figure 15. The potential energy curve for the reaction path shown in Figure 14. B' - G' (green) indicates second loop with the same energy curve as B - G. A'" indicates cluster structure A with a full reaction cycle completed. The dashed line shows the gas phase reaction. Transition states are given in two-letter names, indicating its reactant and product. Adopted from paper $\mathbf{V}$.

From the activation energies the reaction rates were calculated and the coupled kinetic equations were solved to simulate the evolution of the concentrations with time. The overall CO production shown in Figure 16 is very slow, unless oxygen vacancies are present. The vacancies will be filled within, approximately, a microsecond and $\mathrm{CO}(\mathrm{g})$ is formed. The role of $\mathrm{Cu}$ and the reactions of $\mathrm{H}_{2}$ needs to be included in the model if creation of $\mathrm{CH}_{3} \mathrm{OH}$ is to be simulated realistically. 


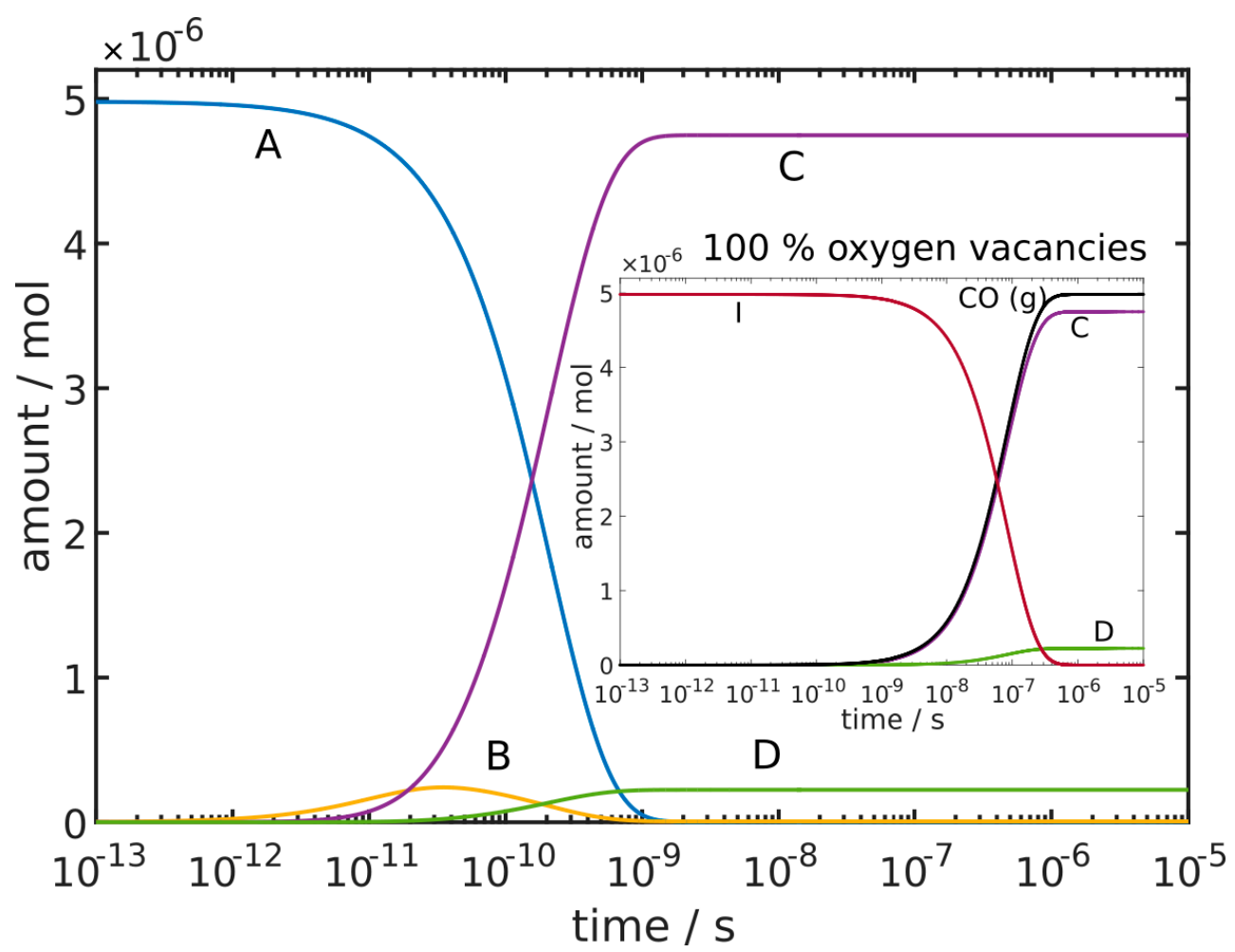

Figure 16. Amounts of the molecular species as a function of time from the reaction kinetics simulation of the stoichiometric cluster (A) and with an excess of $\mathrm{CO}_{2}$. (Inlet) Amounts as a function of time from reaction kinetics simulation of the oxygen vacancy structure (I). Adopted from paper $\mathbf{V}$.

In paper VI the IR spectra of $\mathrm{CO}_{2}$ and $\mathrm{H}_{2}$ interacting with $\mathrm{ZrO}_{2}$ powder and $\mathrm{Cu}$ metal powder under conditions that correspond to the catalyzed $\mathrm{CH}_{3} \mathrm{OH}$ production process were studied experimentally and compared to the results obtained from the theoretical computations. Surface structures and gas-phase molecules were identified through the spectral lines by matching them to specific vibrational modes from the literature and from the new computational results. The IR-spectra arising from experiments with $\mathrm{CO}_{2}$ and $\mathrm{H}_{2}$ interacting with $\mathrm{ZrO}_{2}$ powder (Figure 17) indicates production of $\mathrm{CO}$ (the $\mathrm{P}$ rotational band of gaseous $\mathrm{CO}$ at 2108 and a peak at $2077 \mathrm{~cm}^{-1}$ which could possibly be due to physisorbed CO), adsorbed formic acid (peaks around 2970, 2885 and $1575 \mathrm{~cm}^{-1}$ ) and possibly formation of bicarbonate groups (peak $1230 \mathrm{~cm}^{-1}$ ). 


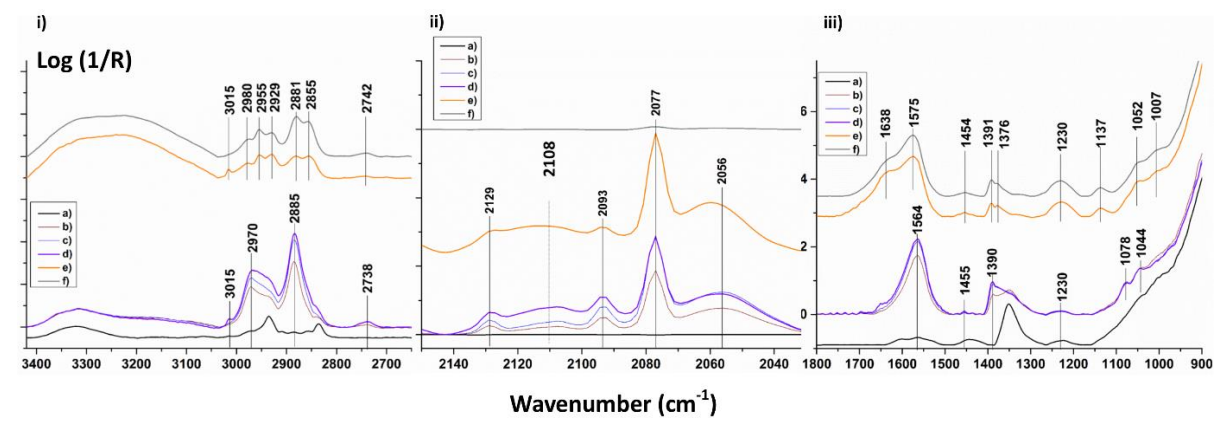

Figure 17. $\mathrm{CO}_{2}$ and $\mathrm{H}_{2}$ interacting with $\mathrm{ZrO}_{2}$ powder. i) $3400-2700 \mathrm{~cm}^{-1}$, ii) 2140 $2040 \mathrm{~cm}^{-1}$, iii) $1800-900 \mathrm{~cm}^{-1}$. The different curves corresponds to measurement at different times during the reaction phase (the lowest curve corresponds to the earliest measurement etc.). Adopted from paper VI.

The IR-spectra arising from $\mathrm{CO}_{2}$ and $\mathrm{H}_{2}$ interacting with pure $\mathrm{Cu}$ metal powder (Figure 18) shows, beside the CO peaks around 2177-2110 $\mathrm{cm}^{-1}$, a large production of $\mathrm{CH}_{4}$ (peak $1304 \mathrm{~cm}^{-1}$ ) not present in the experiment with pure $\mathrm{ZrO}_{2}$ case. There is also a small peak indicating surface bonded methanol at $1033 \mathrm{~cm}^{-1}$.

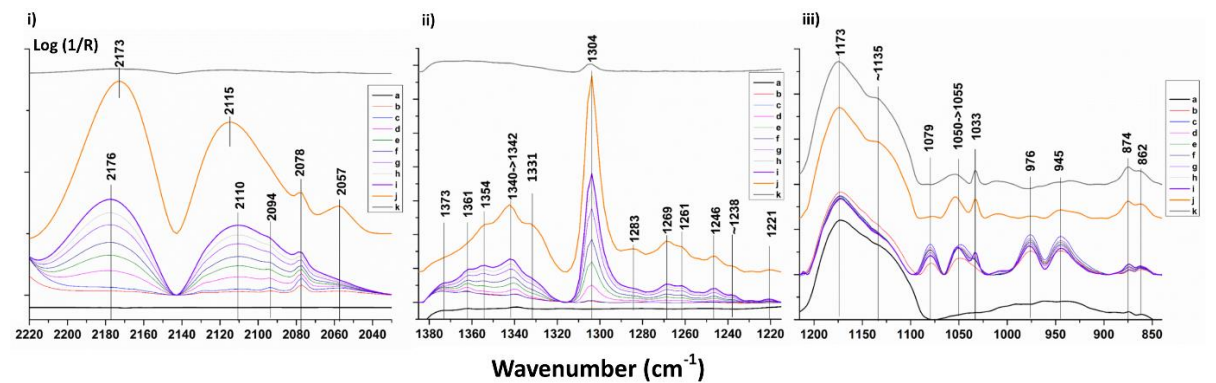

Figure 18. $\mathrm{CO}_{2}$ and $\mathrm{H}_{2}$ interacting with $\mathrm{Cu}$ metal powder. i) $2220-2040 \mathrm{~cm}^{-1}$, ii) $1380-1220 \mathrm{~cm}^{-1}$, iii) $1200-850 \mathrm{~cm}^{-1}$. The different curves corresponds to measurement at different times during the reaction phase (the lowest curve corresponds to the earliest measurement etc.). Adopted from paper VI.

The identified species can be used to locate surface structures in the reaction path. This gives important information that help to decipher the reaction mechanism of the $\mathrm{CO}_{2}$ conversion and, ultimately, may aid in improving the methanol synthesis process. 


\section{References}

1. CRC Handbook of chemistry and physics 90th ed. 2009, 12-222 Taylor \& Francis group, LLC

2. R.F. Davis, Institute of physics conference series 137, 1-6 (1994)

3. Rebecca Cheung, Silicon carbide microelectromechanical systems for harsh environments, 2006, Imperial College Press

4. L. S. Ramsdell, American Mineralogist, 32, 64-82 (1947)

5. J. A. Cooper, A. Agarwal, Proceedings of the IEEE, 90, 6, 956-968 (2002)

6. T. Kimoto, Jpn. J. Appl. Phys. 54, 040103 (2015)

7. T. Kimoto, Tech. Dig. VLSI Technology Symp., p. 9 (2010)

8. J. Millán, P. Godignon, X. Perpiñà, A. Pérez-Tomás, J. Rebollo, IEEE Transactions on Power Electronics, 29, 2155-2163 (2014)

9. C. Buttay, D. Planson, B. Allard, D. Bergogne, P. Bevilacqua, C. Joubert, M. Lazar, C. Martin, H. Morel, D. Tournier, C. Raynaud, Materials Science and Engineering B, 176, 283-288 (2011)

10. V. E. Chelnokov, A. L. Syrkin, Materials Science and Engineering B, 46, 248-253 (1997)

11. A. A. Lebedev and V. E. Chelnokov, Semiconductors, 33, 999 (1999)

12. http://www.ioffe.ru/SVA/NSM/Semicond/AlN/ebasic.html

13. H. Pedersen, S. Leone, O. Kordina, A. Henry, S. Nishizawa, Y. Koshka, and E. Janzén, Chem. Rev., 112, 2434 (2012)

14. F. La Via, M. Camarda, and A. La Magna, Applied Physics Reviews 1, 031301 (2014)

15. T. Kunstmann, H. Anger, J. Knecht, S. Veprek, N. W. Mitzel, H. Schmidbaur, Chem. Mater., 7, 1675 (1995)

16. G. Valente, C. Cavallotti, M. Masi, C. Carrà, J. Cryst. Growth, 230, 247 (2001)

17. S. Nigam, H. J. Chung, A. Y. Polyakov, M. A. Fanton, B. E. Weiland, D. W. Snyder, M. Skowronski, J. Cryst. Growth, 284, 112 (2005)

18. A. Veneroni, F. Omarini, M. Masi, Cryst. Res. Technol., 40, 967 (2005)

19. D. M. Etheridge, L .P. Steele, R. L. Langenfelds, R. J. Francey, J. M. Barnola and V. I. Morgan. 1998. Historical $\mathrm{CO}_{2}$ records from the 
Law Dome DE08, DE08-2, and DSS ice cores. In Trends: A Compendium of Data on Global Change. Carbon Dioxide Information Analysis Center, Oak Ridge National Laboratory, U.S. Department of Energy, Oak Ridge, Tenn., U.S.A.

20. H. H. Rogner, Annual Review of Energy and the Environment, 22(1), 217-262 (1997)

21. S. Shafiee, E. Topal, Energy Policy, 37, 181-189 (2009)

22. R. Sedjo, B. Sohngen, Annual Reviews. 4, 127-144 (2012)

23. J. Ma, N. N. Sun, X. L. Zhang, N. Zhao, F. K. Mao, W. Wei and Y. H. Sun, Catal. Today, 148, 221-231 (2009)

24. W. Wang, S. Wang, X. Ma and J. Gong, Chem. Soc. Rev., 40, 37033727 (2011)

25. Gadi Rothenberg, Catalysis: Concepts and green applications, WileyVCH: Weinheim, ISBN 978-3-527-31824-7

26. K. J. Laidler and J. H. Meiser, Physical Chemistry (Benjamin/Cummings 1982) p.780 ISBN 0-8053-5682-7

27. F. Arena, G. Italiano, K. Barbera, S. Bordiga, G. Bonura, L. Spadaro and F. Frusteri, Appl. Catal., A, 350, 16-23 (2008)

28. T. Inui, T. Takeguchi, Catal. Today, 10, 95-106 (1991)

29. B. J. Liaw and Y. Z. Chen, Appl. Catal., A, 206, 245-256 (2001)

30. F. Arena, K. Barbera, G. Italiano, G. Bonura, L. Spadaro and F. Frusteri, J. Catal., 249, 185-194 (2007)

31. M. Saito and K. Murata, Catal. Surv. Asia, 8, 285-294 (2004)

32. J. Liu, J. Shi, D. He, Q. Zhang, X. Wu, Y. Liang and Q. Zhu, Appl. Catal., A, 218, 113-119 (2001)

33. X. An, J. L. Li, Y. Z. Zuo, Q. Zhang, D. Z. Wang and J. F. Wang, Catal. Lett., 118, 264-269 (2007)

34. R. Raudaskoski, M. V. Niemela and R. L. Keiski, Top. Catal., 45, 57-60 (2007)

35. X. M. Guo, D. S. Mao, S. Wang, G. S. Wu and G. Z. Lu, Catal. Commun., 10, 1661-1664 (2009)

36. J. Toyir, P. R. de la Piscina, J. L. G Fierro, N. Homs, Appl. Catal. B, 34, 255-266 (2001)

37. J. Toyir, P. R. de la Piscina, J. L. G Fierro, N. Homs, Appl. Catal. B 29, 207-215 (2001)

38. K. T. Jung and A. T. Bell, Catal. Lett., 80, 63-68 (2002)

39. E. Schrödinger, Phys. Rev., 28, 1049-1070 (1926)

40. M. Born, J. R. Oppenheimer, Ann. Phys., 84, 457-484 (1927)

41. W. Pauli, Zeitschrift für Physik., 31, 765-783 (1925)

42. J. Slater, H. C. Verma, Phys. Rev., 34, 1293-1322 (1929) 
43. D. R. Hartree, Math. Proc. Camb. Philos. Soc., 24, 89-110 (1928)

44. P. Atkins, J. de Paula, Atkins' Physical Chemistry 9th edition OUP Oxford, 2010

45. A. Szabo, N. S. Ostlund, Modern Quantum Chemistry, McGraw-Hill Publishing, 1989, First Edition, Revised

46. C. C. J. Roothaan, Rev. Mod. Phys., 23, 69 (1951)

47. C. J. Cramer Essentials of Computational Chemistry. 2nd edition, Chichester, John Wiley \& Sons, Ltd. (2004). pp. 203-248

48. C. D. Sherrill, H. F. Schaefer III, Advances in Quantum Chemistry., 34, 143-269 (1999)

49. C. Møller and M. S. Plesset, Phys. Rev., 46, 618-22 (1934)

50. J. Cizek, J. Chem. Phys., 45, 4256 (1966)

51. G. E. Scuseria, C. L. Janssen, and H. F. Schaefer III, J. Chem. Phys., 89, 7382-87 (1988)

52. L. H. Thomas, Proc. Cambridge Phil. Soc., 23, 542-548 (1927)

53. E. Fermi, Z. Physik, 48, 73-79 (1928)

54. P. Hohenberg and W. Kohn, Phys. Rev. B, 136, 864-871 (1964)

55. W. Kohn and L. J. Sham, Phys. Rev. A, 140, 1133-1138 (1965)

56. A. D. Becke, J. Chem. Phys., 140, 18A, 301-18 (2014)

57. J. P. Perdew, Phys. Rev. B, 33, 8822 (1986)

58. A. D. Becke, Phys. Rev. A, 38, 3098 (1988)

59. C. Lee, W. Yang, R.G. Parr, Phys. Rev. B, 37, 785 (1988)

60. A. D. Becke, J. Chem. Phys., 98, 5648-52 (1993)

61. J. C. Slater Phys. Rev., 36, 57 (1930)

62. S. F. Boys, Proc. Roy. Soc., A, 200, 542 (1950)

63. R. McWeeny, Dissertation, Oxford 1948

64. R. McWeeny, Nature, 166, 21-22 (1950)

65. W. J. Hehre, R. F. Stewart, and J. A. Pople, J. Chem. Phys., $512657-$ 64 (1969)

66. J. B. Collins, P. v. R. Schleyer, J. S. Binkley, and J. A. Pople, J. Chem. Phys., 64, 5142-51 (1976)

67. T. H. Dunning Jr., J. Chem. Phys., 90, 1007-23 (1989)

68. R. A. Kendall, T. H. Dunning Jr., and R. J. Harrison, J. Chem. Phys., 96, 6796-806 (1992)

69. J. S. Binkley, J. A. Pople, and W. J. Hehre, J. Am. Chem. Soc., 102, 939-47 (1980)

70. R. Ditchfield, W. J. Hehre, and J. A. Pople, J. Chem. Phys., 54, 724 (1971) 
71. W. J. Hehre, R. Ditchfield, and J. A. Pople, J. Chem. Phys., 56, 2257 (1972)

72. A. D. McLean and G. S. Chandler, J. Chem. Phys., 72, 5639-48 (1980)

73. T. H. Dunning Jr. and P. J. Hay, in Modern Theoretical Chemistry, Ed. H. F. Schaefer III, Vol. 3 (Plenum, New York, 1977) 1-28

74. P. J. Hay and W. R. Wadt, J. Chem. Phys., 82, 270-83 (1985)

75. D. Andrae, U. Haeussermann, M. Dolg, H. Stoll, and H. Preuss, Theor. Chem. Acc., 77, 123-41 (1990)

76. D. A. McQuarrie, J. D. Simon, Molecular Thermodynamics, University Science Books, Sausalito California 1999

77. L. Boltzmann, Wiedemann's Annalen, 22, 291-294 (1884)

78. J. W. Gibbs, Elementary Principles in Statistical Mechanics. 1902, New York: Charles Scribner's Sons

79. https://materials.springer.com/isp/crystallographic/docs/sd_1628877, Springer-Verlag GmbH, Heidelberg, (C) 2016

80. T. H. Peng, Y. F. Lou, S. F. Jin, W. Y. Wang, W. J. Wang, G. Wang, X. L. Chen, Powder Diffraction, 24, 311-314 (2009)

81. D. K. Smith, H. W. Newkirk Acta Crystallogr. 18, 983 (1965)

82. Gaussian 09, M. J. Frisch, G. W. Trucks, H. B. Schlegel, G. E. Scuseria, M. A. Robb, J. R. Cheeseman, G. Scalmani, V. Barone, G. A. Petersson, H. Nakatsuji, X. Li, M. Caricato, A. Marenich, J. Bloino, B. G. Janesko, R. Gomperts, B. Mennucci, H. P. Hratchian, J. V. Ortiz, A. F. Izmaylov, J. L. Sonnenberg, D. Williams-Young, F. Ding, F. Lipparini, F. Egidi, J. Goings, B. Peng, A. Petrone, T. Henderson, D. Ranasinghe, V. G. Zakrzewski, J. Gao, N. Rega, G. Zheng, W. Liang, M. Hada, M. Ehara, K. Toyota, R. Fukuda, J. Hasegawa, M. Ishida, T. Nakajima, Y. Honda, O. Kitao, H. Nakai, T. Vreven, K. Throssell, J. A. Montgomery, Jr., J. E. Peralta, F. Ogliaro, M. Bearpark, J. J. Heyd, E. Brothers, K. N. Kudin, V. N. Staroverov, T. Keith, R. Kobayashi, J. Normand, K. Raghavachari, A. Rendell, J. C. Burant, S. S. Iyengar, J. Tomasi, M. Cossi, J. M. Millam, M. Klene, C. Adamo, R. Cammi, J. W. Ochterski, R. L. Martin, K. Morokuma, O. Farkas, J. B. Foresman, and D. J. Fox, Gaussian, Inc., Wallingford CT, 2016.

83. H. B. Schlegel, J. Comp. Chem., 3, 214-218 (1982)

84. C. Peng, P. Y. Ayala, H. B. Schlegel, M. J. Frisch, J. Comp. Chem., 17, 49-56 (1996)

85. C. Peng, H. B. Schlegel, Isr. J. Chem., 33, 449-54 (1993)

86. T. A. Halgren, W. N. Lipscomb, Chem. Phys. Lett., 49, 225-2329 (1977)

87. P. Sukkaew, Ö. Danielsson, O. Kordina, E. Janzén, L. Ojamäe, J. Phys. Chem. C, 121(2), 1249-1256 (2017) 
88. K. Reuter, M. Scheffler, Phys. Rev. B: Condens. Matter Mater. Phys., 73(4), 045433 (2006)

89. M. Svanqvist and K. Hansen, Eur. Phys. J. D, 56, 199 (2010) 
Paper I-VI 


\section{Papers}

The papers associated with this thesis have been removed for copyright reasons. For more details about these see:

http://urn.kb.se/resolve?urn=urn:nbn:se:liu:diva-148757 